\title{
Analyzing Interactions between Japanese Ports and the Maritime Silk Road Based on Complex Networks
}

\author{
Zhi-Hua Hu (D), ${ }^{1}$ Chan-Juan Liu, ${ }^{1}$ and Paul Tae-Woo Lee ${ }^{2}$ \\ ${ }^{1}$ Logistics Research Center, Shanghai Maritime University, Shanghai 20135, China \\ ${ }^{2}$ Ocean College, Zhejiang University, Zhoushan 316021, China \\ Correspondence should be addressed to Zhi-Hua Hu; zhhu@shmtu.edu.cn
}

Received 12 March 2020; Accepted 21 April 2020; Published 15 May 2020

Guest Editor: Lei Xie

Copyright (c) 2020 Zhi-Hua Hu et al. This is an open access article distributed under the Creative Commons Attribution License, which permits unrestricted use, distribution, and reproduction in any medium, provided the original work is properly cited.

This article considers how the Japanese ports interact with the ports of China and along the 21st century Maritime Silk Road (MSR) while they are embedded in the global port network, especially in the context of China's Belt and Road Initiative. At a port level, it primarily uses connectivity analysis to analyze the port relations and significances in the maritime network. In contrast, at the network level, it applies the methods from network sciences to analyze the significances of these maritime networks and the interactions among the maritime networks of Japan, China, and MSR. This article extracts a large-scale maritime network from ports and vessels' profiles and data of vessels' Automatic Identification System (AIS). It then examines the relations among the networks (including Japan, China, MSR, and global ports) after defining the maritime networks, network generation schemes, and port network analysis tools. Based on the analysis results and findings, this study draws some implications for regional ports and shipping development and the global supply network.

\section{Introduction}

A maritime system consists of ports and shipping lines [1]. A global maritime network undertakes $80-90 \%$ cargo trade in the world, and its traffic is even estimated to increase by $240-1,209 \%$ by 2050 [2]. This article considers a maritime country as a network of ports. China initiated the Belt and Road Initiative (BRI) comprising of the 21st century Maritime Silk Road (MSR) and the Silk Road Economic Belt (SREB) in 2013 [3]. They also can be taken as maritime networks consisting of the ports and vessel flows along the BRI or MSR. The ports, countries with ports, and regional port systems are interweaved in the complicated global port and shipping networks. Thus, this study attempts to raise and answer a research question: how do the maritime networks represent the country- and region-level interactions embedded in the global maritime network?

China publicly released a document entitled "Vision and Actions on Jointly Building Silk Road Economic Belt and 21st-Century Maritime Silk Road" [3, 4]. The document proposed the principles and framework which form the foundation of the BRI, including two parts, MSR and SREB. This article investigates the relation between Japan and MSR. The 21st century Maritime Silk Road goes from China's coast to Europe through the South China Sea and the Indian Ocean in one route and from China's coast through the South China Sea to the South Pacific in the other [5]. Since the inception of the BRI in 2013, it has motivated researchers, businessmen, and policy-makers to address its impact in a multidimensional way. The official document of MSR does not include Japan. However, Japan is an ancient maritime country with numerous maritime ports and advanced maritime transport [6]. It locates near one end of the MSR. Most importantly, Japan is an important trade partner of China.

Japan has begun to pay more and more attention to the BRI with increasing anticipations [7]. From 2013 to 2015, the Japanese government and the Diets Committee have discussed the Asian Infrastructure Investment Bank (AIIB) membership issue intensively. Only after 2015, the discussion covered the BRI with a wider range of topics. By looking at responses by the Japanese government, the initial response 
until 2016 was "nonparticipation"; however, after 2017, the government has shifted attitude to "conditional engagement" through business cooperation in the third countries, especially plus-sum dimension [8].

$\mathrm{Hu}$ et al. [1,9] have established a port and shipping data system using the data from the Internet and commercial providers. Their studies preprocessed the data of maritime ports (6945 ports), terminals (more than 14322 terminals), and berths based on various port data categories and verified by web crawlers and long-time manual processing. They obtained the vessel profiles mainly by web crawlers and so they may not be complete when comparing the real set of active vessels in the world. The ports and vessels' profiles may be changed, and seemingly no official or commercial organization manages such data centrally. Therefore, the acquisition and verification of these data are time-consuming. We generated the shipping connections among maritime ports from the vessels' Automatic Identification System (AIS) $(3,000,000$ vessels) data of 2016. There is an AIS data-sharing network in the world to ensure vessel traveling safety [10]. The AIS data may be recorded in units of second or minute for each vessel when the AIS devises have been installed. Therefore, the AIS data volume is massive. By the present technologies used by us, it will take at least two months to process the data of 2016. From the vessel tracks recorded in AIS, we identified the vessels' calling sequences of ports. The data system does not collect the cargo volumes or containers carried by vessels or handled by maritime ports. Therefore, we used the vessels' weight capacities as estimates of the flows of vessels. As described above, the vessels' calling sequences of ports can be utilized and so we can establish a maritime network (maritime ports and vessel flows) as the base of this study.

This study formulates Japan by a network of its ports and vessel flows among the ports, while the country is not isolated but is connected to other ports, countries, and the global maritime network, as well as China. Simultaneously, China, different countries, and even the global maritime system are all such maritime networks in the global maritime network. The MSR consists of a group of countries, especially with maritime ports and transport connections, which also contribute to a maritime network.

In the era of big data, the bridge of data and qualitative methods emerge in industries [11]. Data storytelling case studies become a vital stream of qualitative researches $[12,13]$. In this study, we take the Japanese maritime network in the global maritime network and interact with various other maritime networks as a case that consists of a series of analysis driven by the data system and network analysis methods (see Section 3).

In the following, we first review the relevant studies that provide general insights into the research question. Then, we develop maritime network analysis methods with eight definitions and computing procedures by extending general network analysis methods. This article used a data system as described in our previous studies [1, 4], and we present the details related to data and visualization in Section 4 . Then, a series of scenarios are analyzed using the data system and proposed network analysis methods. Finally, we discuss the study's empirical findings and conclusions with implications for theory and future research.

\section{Background and Literature Review}

2.1. Network Analysis. The study of networks has a long history in graph theory and sociology. The modern chapter of network science emerged in the background of complexity, complex network, and complex system. The most explosive works in network sciences are helpful to the study of random networks in graph theory [14] and the social network [15]. Various complex networks exist in telecommunication networks, computer networks, biological networks, cognitive and semantic networks, and social networks. The emergence of network science presents the following natures: interdisciplinary, empirical, and datadriven, quantitative and mathematical, and computational nature. Thus, many scholars developed various models and algorithms by using principles and technologies in mathematics and computer sciences for analyzing the network natures and characteristics by considering distinct nodes (elements, actors, nodes, or vertices) and the connections (links or edges). Network science provides various methods to assess the node, edge, and network complexities (e.g., centrality analysis [15] and link prediction [16]), detect the network structures (e.g., clustering and community analysis $[17,18]$ ), and examine the network behaviors (e.g., synchronization and diffusion $[19,20])$.

In this study, upon network science, the maritime networks and their relations are examined. We formulate the countries and regions as maritime networks and their interactions. Thus, the methods in network science can be used and tuned to analyze the shipping, cargo, and trade relations in the port, country, region, and global levels with different granularities of stakeholders.

2.2. Maritime Networks. In a maritime network, a maritime port itself is a hierarchical organization generally with some terminals that contain berths as primary vessel handling facilities; additionally, a port is also a part of a port city that borders with its hinterlands [1]. Due to these hierarchies, the maritime network is geographically a multilayer multiscale system. Meanwhile, it is also associated with logistics, supply chain, industrial chain, trade, and even societies and environments. In this article, we restrict the maritime network to a network of ports and shipping connections; then, we investigate the relations between ports and countries (or independent economies and regions) based on this network.

The maritime network studies can be categorized into three by the method used. First, the maritime networks are studied by network programming to optimize the network structures or deploy the resources operating the networks $[21,22]$. Second, many studies investigate the characteristics of finely modeled networks by using the complex network and social network analysis methods [23-25]. Third, the maritime networks are studied broadly by using comprehensive methods [3, 4]. This article belongs to the second category. In Table 1, we reviewed ten studies and identified a set of 
TABLE 1: Maritime network studies using network analysis methods.

\begin{tabular}{|c|c|c|c|}
\hline No. & Articles & Networks & Analysis methods \\
\hline 1 & {$[26]$} & $\begin{array}{c}\text { (1) Containerized maritime network (1164-1342 vessels and } 330-390 \\
\text { ports); (2) general cargo maritime network (1515-1654 vessels and } \\
938-1232 \text { ports); (3) the data were queried from the Lloyd's Register } \\
\text { database (generated using AIS data). }\end{array}$ & Centrality analysis. \\
\hline 2 & {$[27]$} & $\begin{array}{c}\text { (1) Containerized maritime network for the East-West corridor from } \\
1995 \text { to } 2011 \text {; (2) the network was constructed by the Containerization } \\
\text { International Yearbooks }(2012) \text {. }\end{array}$ & $\begin{array}{l}\text { Degree centrality and distribution, } \\
\text { concentration, and regional network analysis. }\end{array}$ \\
\hline 3 & {$[23]$} & $\begin{array}{l}\text { The Greek Maritime Transportation Network (GMN) is a maritime } \\
\text { transportation system that connects } 229 \text { ports among regions of Greece. }\end{array}$ & $\begin{array}{l}\text { Centrality, clustering, modularity, average path } \\
\text { length, and degree distribution analysis. }\end{array}$ \\
\hline 4 & {$[25]$} & $\begin{array}{l}\text { A network (2001-2012) among } 17 \text { regions comes from the International } \\
\text { Containerization (CI-Online) database that provides container } \\
\text { deployment data (in TEU) among world regions of the top } 100 \text { container } \\
\text { lines in terms of the total TEU capacity, and it updates monthly. }\end{array}$ & Centrality and vulnerability analysis. \\
\hline 5 & {$[28]$} & $\begin{array}{l}\text { The baseline container shipping network (2012) has } 1113 \text { nodes and } \\
15916 \text { links obtained from Lloyd's List Intelligence. }\end{array}$ & $\begin{array}{l}\text { Centrality, community, degree distribution, and } \\
\text { vulnerability analysis. }\end{array}$ \\
\hline
\end{tabular}

(1) The maritime container transportation network consisted of 39 major container ports, including the 18 major container ports in East Asia, with a throughput of a minimum of 1.5 million TEUs. in 2013; (2) edges

$6 \quad$ [24] between ports are weighted by the weekly transportation capacity (in TEUs) deployed by the top 20 liner shipping companies; (3) the typical transit time between pairs of ports is estimated based on http://www.

Centrality analysis. searates.com.

\begin{tabular}{|c|c|c|c|}
\hline 7 & [29] & $\begin{array}{c}\text { (1) A multiplex shipping network used the data on liner shipping services } \\
\text { in the Americas for the } 32 \text { countries and the } 139 \text { container ports located } \\
\text { in them; (2) the primary data source is the Containerization } \\
\text { International Yearbook (2011). }\end{array}$ & $\begin{array}{l}\text { Centrality, clustering, attack simulation, and } \\
\text { vulnerability analysis. }\end{array}$ \\
\hline 8 & {$[30]$} & $\begin{array}{l}\text { (1) Created a container shipping network by using the data from } \\
\text { Alphaliner in } 2014 ;(2) \text { the network comprises } 439 \text { nodes and } 2331 \text { edges. }\end{array}$ & $\begin{array}{l}\text { Centrality, core-periphery, and community } \\
\text { analysis. }\end{array}$ \\
\hline 9 & [31] & $\begin{array}{l}\text { Based on the AIS data, from January } 2014 \text { to March 2015, three maritime } \\
\text { networks were built: the container shipping network has } 577 \text { nodes and } \\
5794 \text { edges; the tanker shipping network has } 708 \text { nodes and 13,935 edges; } \\
\text { the bulk carrier shipping network has } 700 \text { nodes and 15,337 edges in the } \\
\text { MSR shipping network. }\end{array}$ & $\begin{array}{l}\text { Degree distribution, centrality, and flow spatial } \\
\text { distribution analysis. }\end{array}$ \\
\hline 10 & [32] & $\begin{array}{c}\text { (1) Used AIS data to build three cargo ship transportation networks (oil } \\
\text { tanker, container ship, and bulk carrier); (2) the container, oil tanker, } \\
\text { and bulk carrier ship networks contain 1488, 2042, and } 1969 \text { ports } \\
\text { individually. }\end{array}$ & $\begin{array}{l}\text { Centrality, degree distribution, attack analysis, } \\
\text { and network robustness assessment. }\end{array}$ \\
\hline 11 & [33] & $\begin{array}{c}\text { The Greek Maritime Network connects } 229 \text { ports via } 231 \text { bidirectional } \\
\text { shipping routes. }\end{array}$ & $\begin{array}{l}\text { Graph density, centrality, clustering, modularity, } \\
\text { and average path length. }\end{array}$ \\
\hline
\end{tabular}

Source: compiled by the authors.

networks and analysis methods: the original data of constructing the networks mainly come from yearbooks, Internet data queries, and AIS data; analysis methods mainly include centrality, attack test, clustering, and community detection.

2.3. Japanese Maritime Network. Japan is a typical maritime country. In our data system, Japan has 994 ports in total, of which 125 ports are considered essential both in international and domestic maritime networks [34]. Maritime ports are critically crucial to the national and local economies. Because Japan is mountainous, major metropolitan areas are all developed on the coastal planes of the country. The three most significant metropolitan areas of Kanto, Chukyo, and Kinki are all developed along with the large terminals, namely, the Bays of Tokyo, Ise, and Osaka, respectively [34].
Historically, large maritime ports have played a critically important role in the economy as well as the urban development of these bay areas.

Developing a maritime system is critically important to Japan. First, Japan heavily depends on the import of raw materials for domestic production and the daily life of people. For instance, Japan imported more than $90 \%$ of energy and more than $60 \%$ of foods from overseas. Japan is a leading hi-tech country, and many industrial products are exported to the world market by seaborne trade. Second, Japan consists of about 6,800 islands, including four main islands. Most cities develop along the coastal lines of the country, and each of them has developed its port. Ports are critical to the local economy and development. Third, the cost of developing Japanese ports is high and increasing due to severe ocean conditions. Port investment is infeasible 
when the government cannot recognize the ports as essential parts of the development strategies of the nation and local governments. Fourth, limited land availability of port cities restricts the Japanese port developments. The marine terminals, logistics activities, and the port cities demand a large volume of lands. Therefore, the governments must optimize the lands' efficiency and develop multiuse modes to cope with these conditions. Due to severe trade and economic dependence on maritime transport and shortage of land resources, Japanese ports and the shipping industry faces fierce competition in domestic markets and the Asian maritime system. South Korea and China both present competitive power in ports and shipping. The interaction between Japan and neighborhoods and the embeddedness in the global maritime network may indicate potential opportunities for the Japanese port system.

2.4. Summary. The network and maritime studies suggest that network formulation of the maritime network of ports and shipping is beneficial to investigate the structures and behaviors of maritime networks. However, existing studies $[26,32]$ mainly focused on a single network for a country of a region, the network analysis methods coupling two or more maritime networks is still in development. Considering Japan and its interactions with other countries or regions, it is challenging to construct large-scale networks for analysis.

\section{Maritime Network Analysis Methods}

3.1. A Systematic Framework. Figure 1 presents a systematic framework for this study. Considering the knowledge of interactions among the global maritime network, Japan, China, and MSR, we develop four modules in this study as a too-level framework. First, the previous study on the Shipping Earth data system $[1,4]$ is the base of this study. Second, we construct the maritime networks as the base of analysis. Third, in the analysis module, eight scenarios are investigated by constructing assessment methods for maritime network analysis. We demonstrate all these data systems, developed concepts, and methods by using the data system.

The global maritime network is defined, followed by general maritime networks. Then, we elucidate two network generation procedures and schemes: we generate a network from a vessel's port calling sequence; we construct a new network from these two interconnected maritime networks. Finally, the network analyzing methods mainly used in this study (Section 5) are given based on the abovementioned network notations. Based on the degree and PageRank centralities, we conceptualize a metric using the flows among nodes as primary (or top- $n$ ) flows and significances of flow interactions among the maritime networks.

\subsection{Maritime Networks}

3.2.1. Structures of Maritime Networks. We denote a global maritime network as $G=(N, E, P, W)$, where $N, E, P, W$ are the port set, connection set, port properties, and connection properties. $E=\{(i, j) \mid i, j \in N\} ; P=\left\{P^{k}\right\}, P^{k}=\left[P_{i}^{k}\right], i \in N$;
$W=\left\{W^{k}\right\}, W^{k}=\left[P_{e}^{k}\right], e \in E$. Here, $k$ is the name or index of properties, and each property is a vector corresponding to the set of nodes or connections. The notations start (e) and end (e) are used to access the two end nodes of a connection $e \in E$. Define the operators innode(i), outnode (i) as the sets of nodes targeting or originating from the node $i$, as denoted by the following:

$$
\begin{gathered}
\operatorname{innode}(i)=\{\operatorname{start}(e) \mid e \in E, \text { end }(e)=i\}, \quad i \in N, \\
\text { outnode }(i)=\{\text { end }(e) \mid e \in E, \operatorname{start}(e)=i\}, \quad i \in N .
\end{gathered}
$$

In (1), the set of nodes entering a node $i$ contains the starting nodes of the edges whose ending nodes are the node $i$. Similarly, the set of nodes leaving a node $i$ contains the ending nodes of the edges whose starting nodes are the node $i$.

Any maritime network is a part of the global maritime network. Given a node subset, $N^{s} \subseteq N$, a maritime network is denoted as $G\left(N^{s}\right)=\left(N^{s}, E\left(N^{s}\right), P\left(N^{s}\right), W\left(N^{s}\right)\right)$ in the following:

$$
\begin{aligned}
& E\left(N^{s}\right)=\left\{(i, j) \mid i \in N^{s}, j \in N^{s}\right\} \subseteq E \\
& P\left(N^{s}\right)=\left\{P^{k}\left(N^{s}\right)\right\}=\left\{\left\{P_{i}^{k} \mid i \in N^{s}\right\}\right\}, \\
& W\left(N^{s}\right)=\left\{W^{k}\left(N^{s}\right)\right\}=\left\{\left\{P_{e}^{k} \mid e \in E\left(N^{s}\right)\right\}\right\} .
\end{aligned}
$$

The maritime network of a given set of ports $N^{s}$ can be reformulated in the form of $G=(N, E, P, W)$ as defined above. Here, the new port set is $N^{s}$. The new edge set contains the edges whose starting and ending nodes that are in $N^{s}$, as denoted by (3). The port property set is a set of properties, where a property is a data vector corresponding to $N^{s}$, as denoted by (4). Similarly, the edge property set is a set of properties, where a property is a data vector corresponding to the edge set computed by (3).

The centrality measures include degree, closeness, and betweenness measures of centrality [15]. These basic centralities assess the importance (in various aspects) of a node in a network.

A vessels' shipping traffic network is different from general connectivity-based networks because a vessel's movement may depend on several previous calling ports [35]. Based on this observation, we develop the network of calling sequences by considering the vessels' movements. Besides, because the final network is a composition of all edges generated by the calling sequences, the final network utilized the local information (the calls to neighbor ports) to reduce the random errors in AIS data [36].

3.2.2. Generating Maritime Networks. In the context of maritime studies, we define a calling sequence (denoting a sequence by $\mathrm{v}$ in a sequence set $V$ ) as a sequence of network nodes and a weight attached to the sequence, namely, $\left(\vec{N}^{v}, W^{v}\right)$, where $\vec{N}^{v}=i_{1}, i_{2}, \ldots, i \vec{N}^{v}, i_{*} \in N$, and a constant weighted is $W^{s}$. The sequence $v$ travels from the port $i_{k}$ to the port $i_{k+j}$. We say that the sequence travels for $j$ jumps. The network of calling sequence is defined by a $\left\{\left(\vec{N}^{v}, W^{v}\right)\right\}$. By $\left\{\left(\vec{N}^{v}, W^{v}\right)\right\}, \quad$ a maritime network 


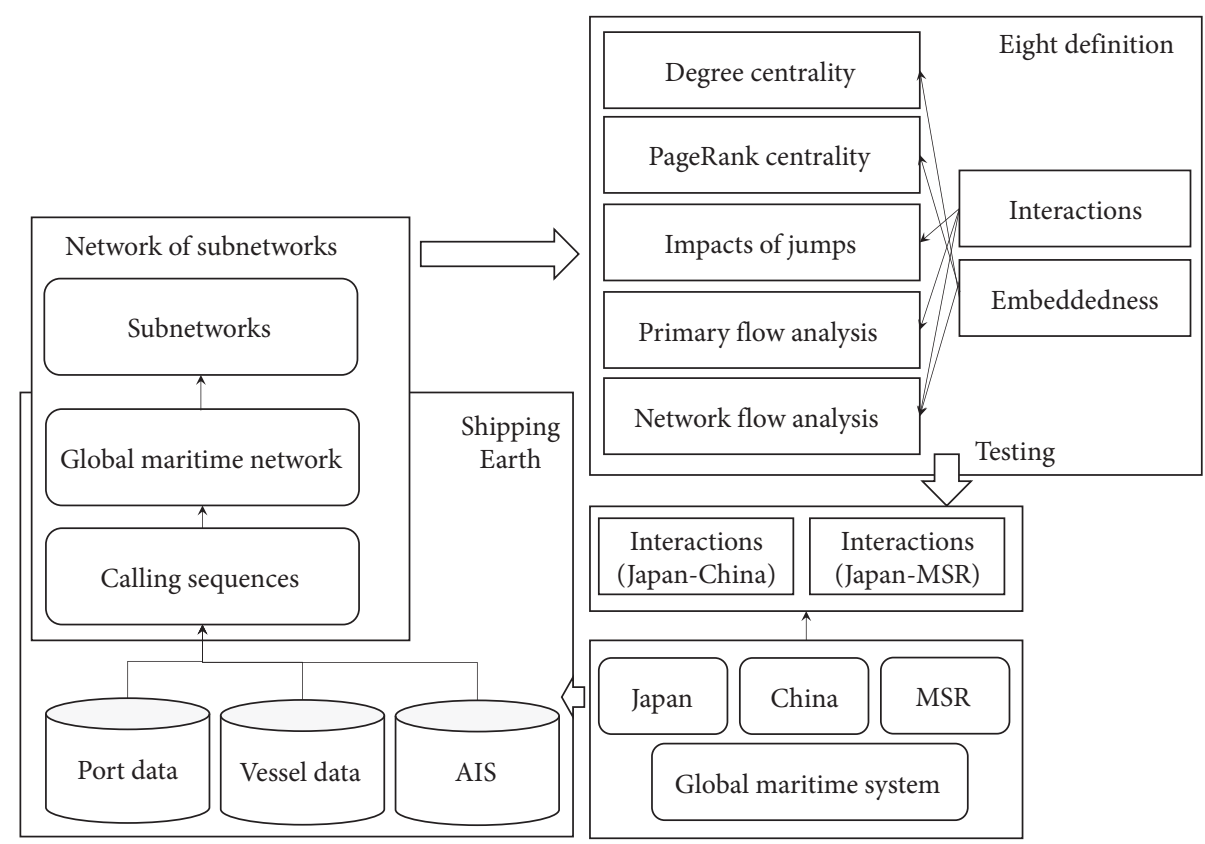

FIgUre 1: A systematic framework.

$G=(N, E, P, W)$ can be generated as (6)-(8). In (8), $W^{* v}$ is used to represent the original weight of the calling sequence, while $W^{v}$ is generated for the network.

$$
\begin{aligned}
N & =\operatorname{set}\left(\cup_{v} \operatorname{set}\left(\vec{N}^{v}\right)\right), \\
E & =\left\{(i, j) \mid \exists v, i, j \in \vec{N}^{v}\right\}, \\
W_{(i, j)}^{v} & =\sum_{\langle i, j\rangle \in \vec{N}^{v}} W^{* v} .
\end{aligned}
$$

In (6)-(8), we generate $N, E, W$ from a set of calling sequences. Notably, a calling sequence visits a series of ports one by one. Therefore, the direct connections from a visited port to an adjacent port just after visiting the port can be extracted from the sequence gradually. That is, a set of $N-1$ connections (edges) can be extracted from a sequence of $N$ ports, as denoted by (7). For a given sequence, we can calculate and determine some properties, e.g., the weight and size of the vessel of this sequence. Therefore, each edge can inherit the property of the sequence, as denoted by (8).

In the abovementioned formulations, only direct transition (one jump) from a port to its adjacent port in $\vec{N}^{v}$ is used to the network $G$. Indeed, the transitions from a port to its successors all can present indirect transitions with a multiplier of possible smaller coefficients. In (9), all transitions from a port to its successor in the calling sequence indicate connections among ports; in (10), the weight of a connection is reduced by a multiplier, $1 /\left(t_{2}-t_{1}\right)$, which indicates that long-distance transition (more jumps) impacts less on the weight. Notably, in (9) and (10), by using $i \notin \vec{N}^{v}\left[\left(t_{1}+1\right) \sim t_{2}\right]$, the jump from node $i$ will "stop" when it meets $i$.

$$
\begin{aligned}
& E=\left\{(i, j) \mid \exists v \in V, t_{1}<t_{2}, t_{2}-t_{1}>j u m p s,\right. \\
& \left.i \notin \vec{N}^{v}\left[\left(t_{1}+1\right) \sim t_{2}\right]: i=\vec{N}^{v}\left[t_{1}\right], j=\vec{N}^{v}\left[t_{2}\right]\right\}, \\
& W_{(i, j)}^{v}=\sum_{\substack{\left.i=\vec{N}^{v} \\
i \notin t_{1}\right], j=\vec{N}^{v}\left[\left(t_{1}+1\right) \sim t_{2}\right], t_{2}-t_{1}>\text { jumps }}} \frac{W_{(i, j)}^{* v}}{t_{2}-t_{1}}, \quad \forall v \in V .
\end{aligned}
$$

As the difference between (9) and (7), they use one jump or multijumps to construct the sets of edges from a sequence. The number of jumps can amend the impacts on the edge properties, as denoted by (10).

Hence, we can set an arbitrary upper boundary number of jumps (jumps $\leq n)$ to generate $E$ and $W_{(i, j)}^{v}$, and so the resulting $\mathrm{E}$ and $W_{(i, j)}^{v}$ are denoted by $\left.E\right|_{j u m p s \leq n}$ and $\left.W_{(i, j)}^{v}\right|_{\text {jumps } \leq n}$. The resulting network will also affect the centrality and network analysis results. Therefore, this notation indicates the settings of the upper boundary jump number for generating networks. In this study, we generate the networks used in the following sections with jumps $\leq 15$. "Jumps" is a new concept introduced to represent the behaviors of the sequence.

$\vec{N}^{v}$ is a time series and other two accompanied series can be defined, $\vec{T}^{v}$ and $\vec{D}^{v}$, which are the visiting times and durations. By using these two series, $\vec{N}^{v}$ can be segmented into short series for periodical pattern analysis.

We can generate a maritime network from a set of maritime networks whose ports come from the original networks, whose port properties aggregate the properties of the ports, and whose edge connections aggregate the weights of connections between the ports of connections. 
Given two maritime networks $\left(N^{a}, N^{b}\right)$, new $E^{c}, P^{c}, W^{c}$ are generated as (11)-(16), where $\otimes$ and $\oplus$ are aggregate operators upon the properties and weights; $E\left(N^{a}, N^{b}\right)$ is a set of connections between $N^{a}$ and $N^{b}$. Notably, we insert two possible new connections into the connection set $E^{c}$ when connections exist between the given networks, as denoted by (13) and (14).

$$
\begin{aligned}
N^{c} & =N^{a} \cup N^{b}, \\
E\left(N^{a}, N^{b}\right) & =\left\{(i, j) \mid i \in N^{a}, j \in N^{b}\right\}, \\
E^{c} & \leftarrow(a, b), \quad \text { if }\left|E\left(N^{a}, N^{b}\right)\right|>0, \\
E^{c} & \leftarrow(b, a), \quad \text { if }\left|E\left(N^{b}, N^{a}\right)\right|>0, \\
P & =\left\{\otimes_{i \in N^{a}}\left(P_{i}^{k}\right), \otimes_{i \in N^{b}}\left(P_{i}^{k}\right) \mid k\right\}, \\
W & =\left\{\oplus_{e \in E\left(N^{a}, N^{b}\right)}\left(W_{e}^{k}\right) \mid(a, b) \in E^{c}\right\} .
\end{aligned}
$$

In (11)-(16), we deduce two maritime networks, $N^{a}$ and $N^{b}$. In (11), the nodes of a top network come from these subnetworks. In (12), an operator computes the edge set between the nodes of two networks. In (13) and (14), if there are edges between two networks, an edge is added to the edge set of the top network. The node and edge property sets are different. Hence, we introduce aggregation operators in (15) and (16). For example, the throughput property of a network is the sum $(\otimes=+)$ of the throughputs of the port nodes of the network. Similarly, the transportation volume between two networks is the sum $(\oplus=+)$ of the volumes of all edges between these two networks.

3.3. Analysis Tools for Maritime Networks. Two categories of network analysis are studied here: node-based and edgebased analysis tools.

3.3.1. Node-Based Analysis. The node-based tools are defined based on centralities in complex networks, namely, the degree centrality and PageRank centrality [37]. The degree centrality can represent the significance of nodes with inflows and outflows (delegating the port throughputs in maritime studies). In contrast, the PageRank centrality can reflect the network significance of a node (delegating some important hub ports in a maritime network).

We derive the definitions of the weighted degree centrality as (17)-(19) [15], where $C^{\text {indegree }}(i)$ and $C^{\text {outdegree }}(i)$ are in- and out-degrees when the network is considered as a directional one, and $C^{\text {degree }}(i)$ is the centrality degree when we consider the network as a bidirectional one. When analyzing connection networks, the degree is simplified to account the connection times, as defined by (20)-(22). $N^{\text {io }}(i)$ is a set of connected nodes, while the number of connected nodes is $\left|N^{\text {io }}(i)\right|$.

$$
\begin{aligned}
C^{\text {indegree }}(i) & =\sum_{\text {end }(e)=i} W_{e}^{k}, \quad \forall i \in N, \\
C^{\text {out degree }}(i) & =\sum_{\text {start }(e)=i} W_{e}^{k}, \quad \forall i \in N, \\
C^{\text {degree }}(i) & =C^{\text {indegree }}(i)+C^{\text {out degree }}(i), \quad \forall i \in N, \\
N^{\text {in }}(i) & =\{j \mid(j, i) \in E\}, \quad \forall i \in N, \\
N^{\text {out }}(i) & =\{j \mid(i, j) \in E\}, \quad \forall i \in N, \\
N^{\text {io }}(i) & =N^{\text {in }}(i) \cup N^{\text {out }}(i), \quad \forall i \in N .
\end{aligned}
$$

In the PageRank centrality, the importance of the nodes pointing to $i$ represents the importance of a node $i$, denoted by inno de (i), while the nodes pointed by connections from $i$ is denoted by outnode(i). The PageRank centrality is conceptually defined by

$$
C^{\text {pagerank }}(i)=c \sum_{j \in \text { innode }(i)} \frac{C^{\text {pagerank }}(j)}{|\operatorname{outnode}(j)|}, \quad i \in N .
$$

The "PageRank" $[38,39]$ centrality is rooted in a random walk of the network. Given a node in a graph, we decide the next node with the "Follow Probability" from the set of alternatives (successors) of the current node (neighbors for the undirected case). Otherwise, when a node has no alternatives (successors), the next node is selected from all nodes. We use the PageRank algorithm implemented in MATLAB 2016.

3.3.2. Edge-Based Analysis. Two edge-based tools are defined: the primary flows among a maritime network, and the flows among two maritime networks in the context of the global maritime network.

The primary flows are top- $\mathrm{N}$ flows between two maritime networks. Given two maritime networks with node sets $N^{a}$ and $N^{b}$, the connections from $N^{a}$ to $N^{b}$ are $E\left(N^{a}, N^{b}\right)$. The flow is denoted by $W_{e}^{\text {flow }}$ for each $e \in E\left(N^{a}, N^{b}\right)$. Hence, the connections can be ranked by the flows decreasingly. The set of the top-N connections is $\Delta^{n}\left(N^{a}, N^{b}\right)$. Here, $n$ is a number indicating $n$ connections in the set.

The mutual maritime flows occur between two maritime networks in the context of a global network. The network flows are assessed in three criteria: number calling sequences, number of calls, and weighted flow volume.

Given two node sets $N^{a}$ and $N^{b}$ as two maritime networks, the three assessment criteria for mutual network flows are $F^{\text {seq }}\left(N^{a}, N^{b}\right), F^{\text {visit }}\left(N^{a}, N^{b}\right)$, and $F^{\text {weight }}\left(N^{a}, N^{b}\right)$ $((24)-(26))$.

$$
\begin{aligned}
& F^{s e q}\left(N^{a}, N^{b}\right)=\sum_{v \in V}\left(\left|N^{a} \cap \vec{N}^{v}\right|>0 \wedge\left|N^{b} \cap \vec{N}^{v}\right|>0\right), \\
& F^{v i s i t}\left(N^{a}, N^{b}\right)=\sum_{v \in V, i \in \vec{N}^{v}}\left(i \in N^{a} \wedge i+1 \in N^{b}\right),
\end{aligned}
$$




$$
F^{\text {weight }}\left(N^{a}, N^{b}\right)=\sum_{e \in E\left(N^{a}, N^{b}\right)} W_{e}^{\text {flow }}+\sum_{e \in E\left(N^{b}, N^{a}\right)} W_{e}^{\text {flow }}
$$

We further explain the abovementioned three criteria. In (24), we compute the number of vessels' calling sequences visiting the two maritime networks (visiting a port in a maritime network and visiting another port in another maritime network), which is approximately equal to the number of vessels calling the two maritime networks. It can answer the general question: how many vessels visit the two maritime networks simultaneously? The number should represent the connection strength of two maritime networks. In (25), if a sequence visits a port in a maritime network and then a port in another maritime network, $F^{\text {visit }}$ will be increased by one. That is to answer the question: how many visits to the two maritime networks? Similarly, by (26), we try to answer: how much volume on the visits between the two networks when the edge property is volume? By these three computing formulas, the relations between the two networks are determined.

3.4. An Example. Considering two calling sequences or maritime ports, $\langle 1,2,3,4,5,6,5,3\rangle$ with a flow of 500 tons and $\langle 2,3,4,5,7,3,1\rangle$ with 700 tons. The berths of the ports 1-7 are $4,4,3,3,5,5$, and 5 individually. Therefore, a network $G=(N, E, P, W)$ can be established:

(1) $N=\{1,2, \ldots, 7\}$

(2) Consider a set of eight edges: $E=\{(1,2)$, $(2,3),(3,4),(5,6),(5,3),(5,7),(7,3),(3,1)\}$

(3) $P=\left\{P^{\text {berths }}\right\}$ and $P^{\text {berths }}=\{4,4,3,3,5,5,5\}$

(4) $W=\left\{W^{\text {flow }}\right\}$ and $W^{\text {flow }}=\{500,1200,1200,1200$, $500,700,700,700\}$

We can identify two maritime networks from the seven maritime ports, namely, $N^{a}=\{1,2,3\}$ and $N^{b}=\{4,5,6,7\}$. Set two aggregate operators $\otimes$ and $\oplus$ to $\sum$. A new network of the submaritime networks $G^{c}=\left(N^{c}, E^{c}, P^{c}, W^{c}\right)$ can be extracted:

$$
\begin{aligned}
& \text { (1) } N^{c}=\{a, b\} \\
& \text { (2) } E^{c}=\{(a, b),(b, a)\} \\
& \text { (3) } P^{c}=\left\{P^{\text {berths }}\right\}, \text { and } P^{\text {berths }}=\{11=4+4+3,18=3+ \\
& 5+5+5\} \\
& \text { (4) } W^{c}=\left\{W^{\text {flow }}\right\}, \text { and } W^{\text {flow }}=\{1200,1900=1200+ \\
& 700\}
\end{aligned}
$$

\section{Data}

In this study, we use the data of more than 300,000 vessels' AIS tracks and 6000 maritime ports of 2016 to construct a maritime network $G=(N, E, P, W)$ by using the methods developed in Section 3. A vessel's track of its positions recorded in AIS can be processed to be a calling sequence of maritime ports. By this process, we can obtain the port calling sequences of all vessels. Within these vessels, only about two of the third can have port calling sequences. Here,
$N$ is a set of maritime ports in the global maritime network; $E$ is a set of connections among ports. We can generate $E$ by the method described in Section 3. $P$ denotes a property, namely, economic entity (ee), $P=\left\{P^{e e}\right\}$. The original weight $\left(W^{* s}\right.$ in (8) and (10)) of a vessel calling sequence is the weight of the vessel.

Use ee $\in\{$ world, Japan, China, MSR $\}$ to represent the complete port set (world), the Japanese port set (Japan) and Chinese port set (China), and a set of ports along the Maritime Silk Road (MSR), $N^{\text {world }}(=N), N^{\text {Japan }}, N^{\text {China }}$, and $N^{M S R}$. Their supplementary sets are denoted by $\varnothing$ (empty set), $\bar{N}^{\text {Japan }}, \bar{N}^{\text {China }}$, and $\bar{N}^{\text {MSR }}$. Additionally, the Japanese ports include two sets, domestic port set $N^{J d}$ and international port set $N^{J i}$. A Japanese maritime port is called if and only if at least a vessel visits at least one port, not in $N^{\text {Japan }}$. We introduce Visits $(n)$ representing the number of vessels visiting Japanese ports for at least $n$ times, as denoted in (27). Besides, in (28), Countries ( $v$ ) computes the number of countries whose ports are visited by the vessel $v$.

$$
\begin{gathered}
\operatorname{Visits}(n)=\sum_{v \in S}\left(F^{\text {seq }}\left(N^{\text {Japan }}, \bar{N}^{\text {Japan }}\right)>n\right), \\
\text { Countries }(v)=\left|\left\{P^{\text {country }}[i] \mid i \in \vec{N}^{v}\right\}\right|, \quad \forall v \in V .
\end{gathered}
$$

Table 2 summarizes the vessels visiting the Japanese ports $N^{J a p a n}$. First, we classify the trading vessels into domestic and international trading vessels. More vessels are international trading vessels visiting the Japanese ports. Only a very few vessels visited Japan once in 2016, while most vessels visited the country for more than ten times. Considering the time of vessel callings, the distributions of vessels to the visiting times (Visits $(i)-V i s i t s(i+1))$ and countries (Countries $(v)$ ) are depicted (see Figure 2).

Further, the distributions of $F^{\text {visit }}$ and $F^{\text {weight }}$ computed from $\left\{\vec{N}^{v}\right\}$ can be depicted for dates and months using $\left\{\vec{T}^{v}\right\}$ and $\left\{\vec{D}^{v}\right\}$ (see Figure 3). The seasonality of the distribution is slight at least for the distributions of $F^{\text {visit }}$ and $F^{\text {weight }}$.

The jumps have impacts on $F^{\text {weight }}, F^{\text {seq }}, N^{i o}$, and $F^{\text {visit }}$ (see Figure 4). Therefore, the choice of the parameter "jumps" is essential. When the number is too small, the impacts of indirect connections among ports on the results are not observable. The "jumps" represent the visiting behavior of vessels to the ports. If a vessel visits port $\mathrm{A}$ just before port $\mathrm{C}$, the number of jumps is one from $\mathrm{C}$ to $\mathrm{A}$; if a vessel visits port $A$ before visiting $B$ and $C$, the number of jumps is two from $\mathrm{C}$ to $\mathrm{A}$ (Section 3 ). In this study, we set the number of jumps to 15 in (9) and (10).

\section{Results and Analysis}

In the following, we construct the maritime networks and analyze the interactions among the maritime networks $\left(N^{\text {Japan }}, N^{\text {China }}, N^{M S R}, \bar{N}^{\text {Japan }}, \bar{N}^{\text {China }}, \bar{N}^{M S R}, N^{J d}\right.$, and $\left.N^{J i}\right)$ in the context of the global network ( $\left.N^{\text {world }}\right)$ by using the node- and edge-based analysis tools. 
TABLe 2: Summary of vessel visits to Japanese ports.

\begin{tabular}{lcr}
\hline Total vessels & $N^{\text {Japan }}$ & 13925 \\
\hline \multirow{2}{*}{ Trading vessels } & $N^{\text {Jomestic }}$ & 6419 \\
& $N^{\text {Jinternational }}$ & 7506 \\
\hline & Visits (200) & 3562 \\
& Visits $(100)$ & 5118 \\
Vessel visits & Visits (50) & 6772 \\
& Visits (20) & 8769 \\
& Visits $(10)$ & 10270 \\
& Visits $(1)$ & 13287 \\
\hline
\end{tabular}

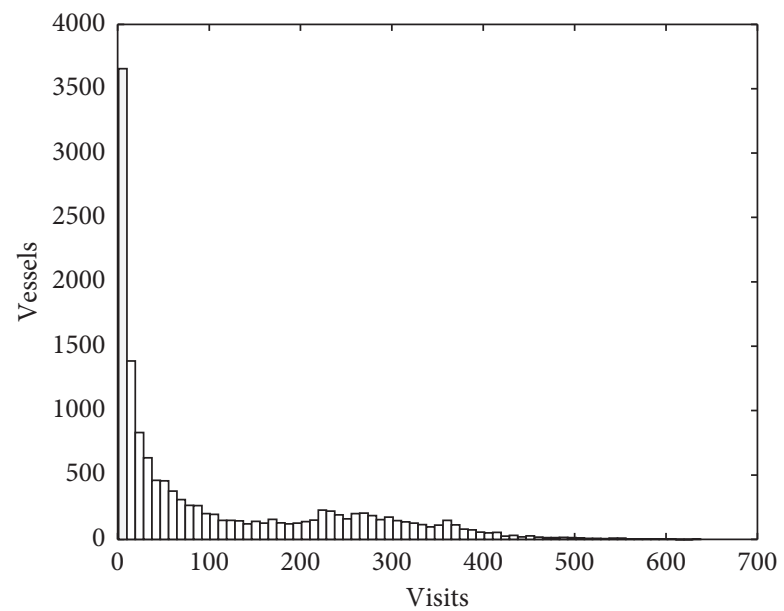

(a)

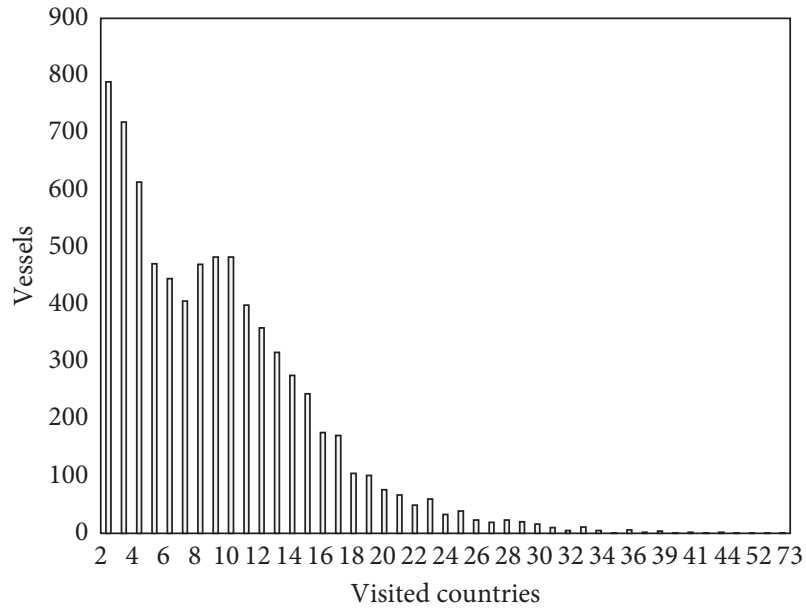

(b)

Figure 2: Vessel visiting times and countries. (a) Visits $(i)-V i s i t s(i+1)$. (b) Countries (v).

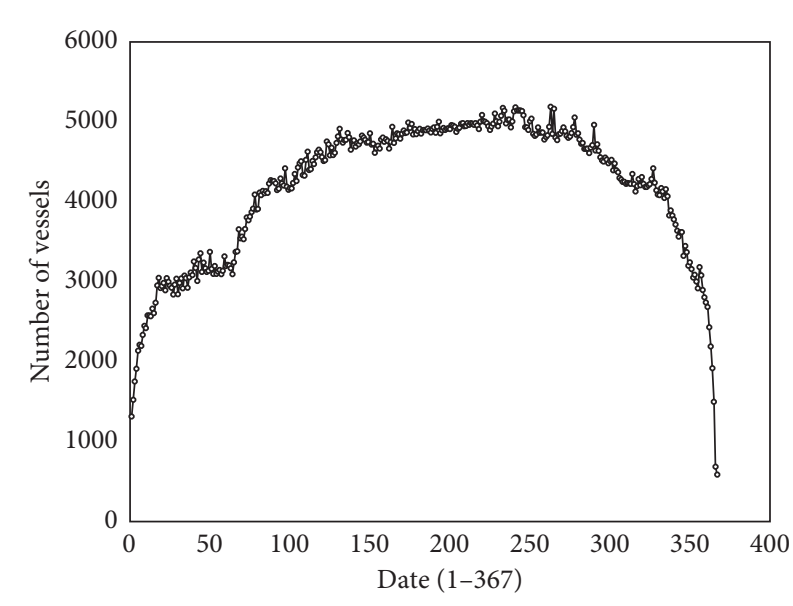

(a)

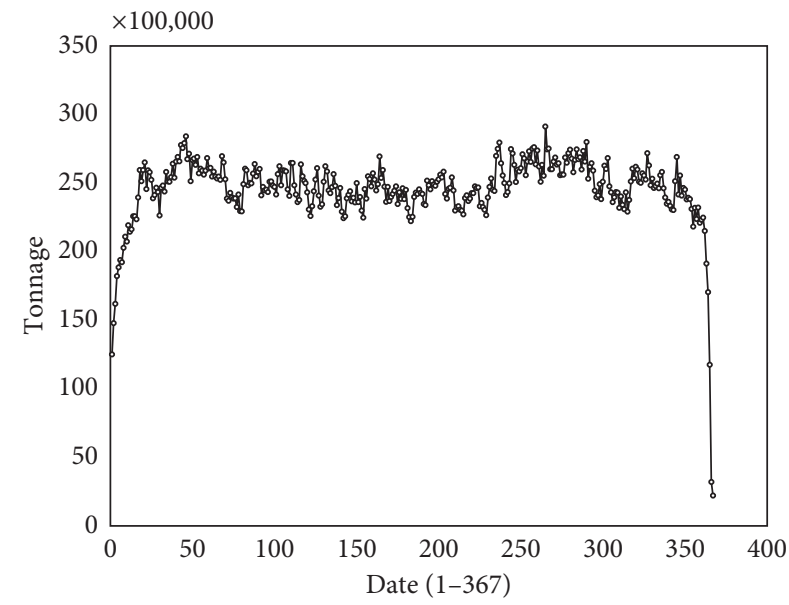

(b)

FIgURE 3: Continued. 


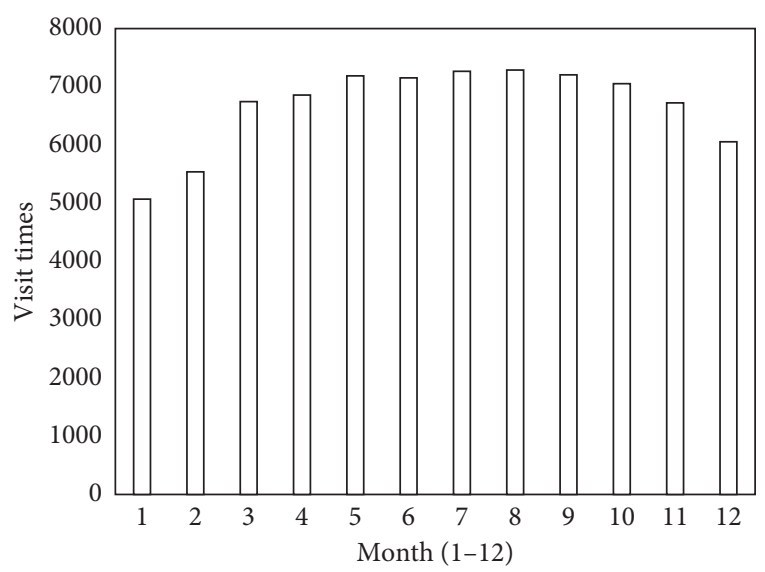

(c)

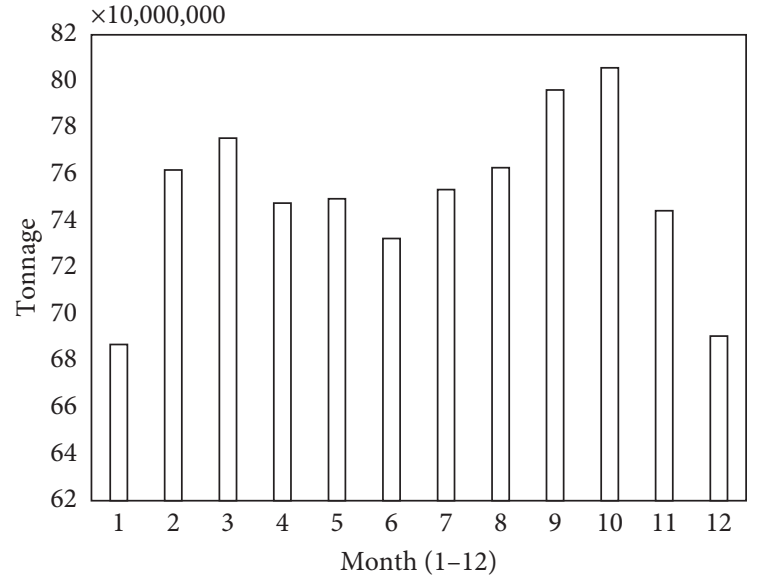

(d)

Figure 3: Periodical vessel visits and flows. (a) $F^{\text {visit }}$ by date. (b) $F^{\text {weight }}$ by date. (c) $F^{\text {visit }}$ by month. (d) $F^{\text {weight }}$ by month.
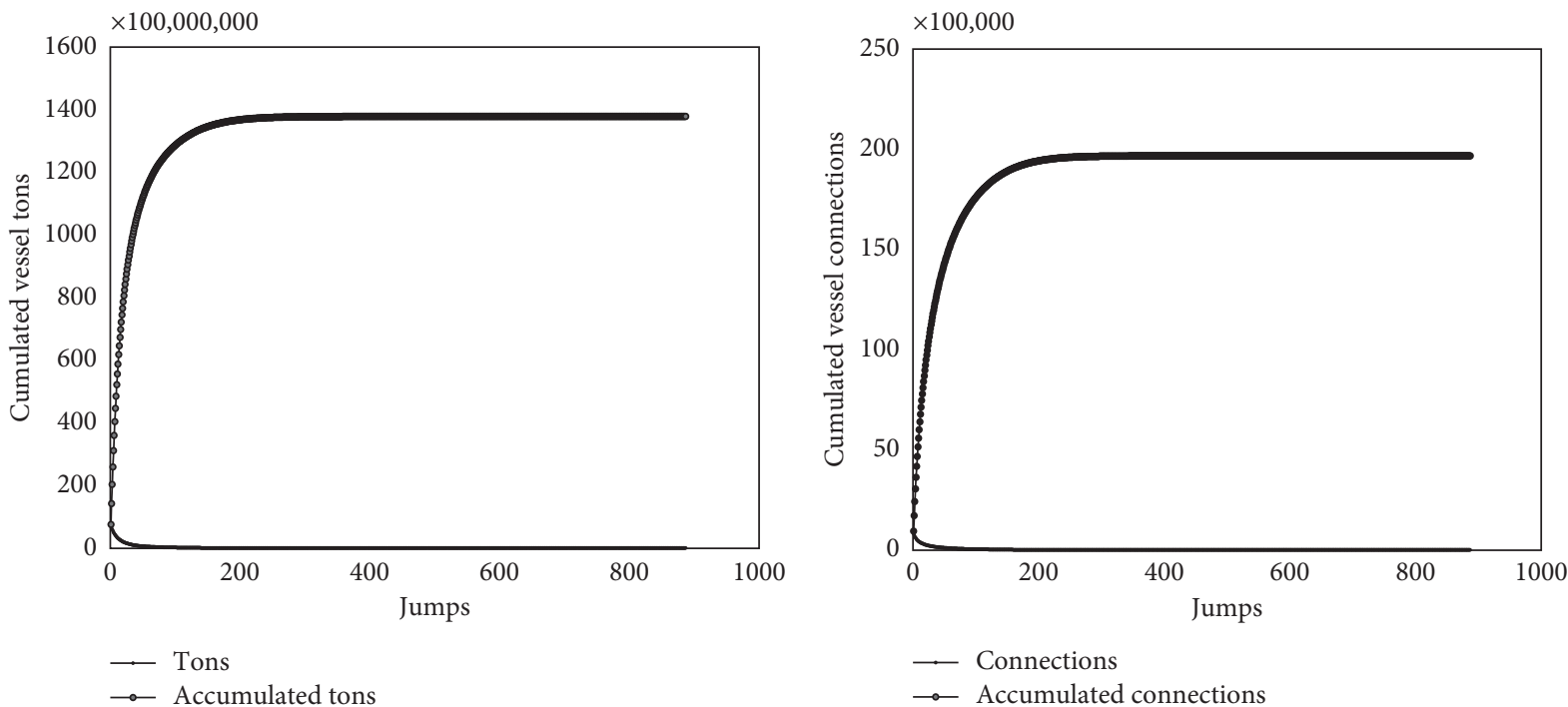

(a)

(b)
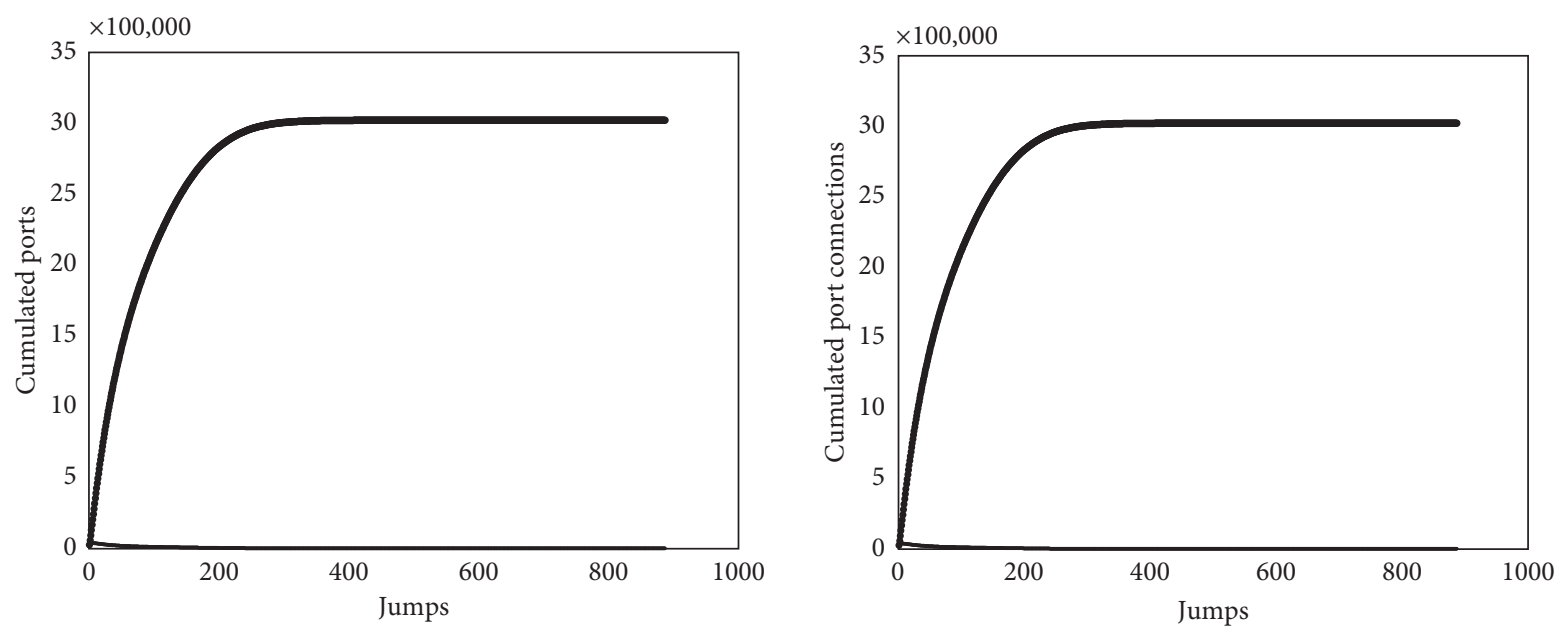

— Ports

$\rightarrow$ Accumulated ports

Port connection

$\rightarrow$ Accumulated port connections

(c)

(d)

FIGURE 4: Japanese port distributions impacted by jumps. (a) $\left.F^{w e i g h t}\right|_{j u m p s \leq n}$. (b) $\left.F^{s e q}\right|_{j u m p s \leq n}$. (c) $\left.N^{i o}\right|_{j u m p s \leq n}$. (d) $\left.F^{v i s i t}\right|_{j u m p s \leq n}$. 
5.1. One-Jump Connections with the World. As defined in (12), The direct connections (jumps $=1, E\left(N^{\text {Japan }}, \bar{N}^{\text {Japan }}\right)$ ) between Japanese ports $\left(N^{\text {Japan }}\right)$ and the world $\left(\bar{N}^{\text {Japan }}\right)$ mean the ones directly connecting the Japanese ports and the ports of all countries/regions (see Figure 5). Here, 26097 connections and 922 ports are involved. In other words, the number of jumps (as defined in Figure 3 ) is one. The vessel connections (see Figures 5(a) and 5(b)) and the top primary flows (see Figures 5(c) and 5(d) for $\Delta^{2000}\left(N^{\text {Japan }}, \bar{N}^{\text {Japan }}\right)$ ) help to identify most maritime trading regions.

5.2. Multijump Connections with the World. All connections between Japanese ports $\left(N^{\text {Japan }}\right)$ and the world $\left(\bar{N}^{\text {Japan }}\right)$ are the ones connecting the Japanese ports and the ports of all countries/regions by various numbers of jumps (jumps $>1$ ) (see Figures 6 and 7). Here, 114673 connections and 2520 ports are involved. The maritime trading regions can be identified (see Figures 6(a) and 6(b)), as well as the top primary flows (see Figures $6(\mathrm{c})$ and $6(\mathrm{~d})$ for $\Delta^{2000}$ $\left.\left(N^{\text {Japan }}, \bar{N}^{\text {Japan }}\right)\right)$. The settings' multijump connections reveal possible indirect maritime trading partners for Japan.

5.3. The Maritime Network of Domestic Trading Flows. The domestic connections (see $E^{J d}$ computed by (29)) can be summarized in terms of port connections, vessel visits $\left(N^{\text {Japan }}\right)$, and flow, as well as the connecting domestic ports (see Table 3). The 149 active ports almost entirely interconnect with each other (see $N^{J d}$ computed by (30)) in the connection graph (see Figure 8 ). The flow throughput of port $i$ is computed by (31)-(34).

$$
\begin{aligned}
E^{J d}= & \left\{(i, j) \mid(i, j) \in E ; i, j \in N^{\text {Japan }}\right\}, \\
N^{J d}= & \left\{j \mid(i, j) \in E ; i, j \in N^{\text {Japan }}\right\} \\
& \cup\left\{j \mid(j, i) \in E ; j, i \in \bar{N}^{\text {Japan }}\right\}, \\
\text { Vessels }(i)= & \sum_{v \in V}\left(\exists j: \vec{N}^{v}[j]=i\right), \\
C^{\text {windegreed }}(i)= & \sum_{e \in E^{J d},} W_{e}^{\text {flow }}, \quad \forall i \in N^{\text {Japan }}, \\
C^{\text {woutdegreed }}(i)=i & \sum_{e \in E^{J d},} W_{e}^{\text {flow }}, \quad \forall i \in N^{\text {Japan }}, \\
C^{\text {wart }(e)=i}(i)= & C^{\text {woutdegreed }}(i)+C^{\text {woutdegreed }}(i) .
\end{aligned}
$$

From the top 20 primary flows (Table 4 ), we can identify the primary port connections, by using $\Delta^{20}\left(N^{\text {Japan }}, N^{\text {Japan }}\right)$. The last three columns are defined by similar formulas, as presented in (24)-(26).

The abovementioned analysis provides tools to identify important or potentially critical domestic ports and maritime transport channels for Japan.
5.4. The Maritime Network of International Trading Flows. From the resulting international trading connections of 149 Japanese ports (Table 5), most Japanese ports $\left(N^{\text {Japan }}\right)$ connect to more than 1000 ports (in $\bar{N}^{\text {Japan }}$ ), as defined in (36) where $E^{J i}$ is given by (35), and only one port is purely a domestic trading port. From the top 20 ports with the most significant flows (Table 6), only one port (Yanai, that is the purely domestic port) is listed. Therefore, Japan is a typical maritime country because its ports are almost international active ports.

$$
\begin{aligned}
E^{J i}= & \left\{(i, j) \mid(i, j) \in E ; i \in N^{\text {Japan }}, j \in \bar{N}^{\text {Japan }}\right\}, \\
N^{J i}= & \left\{j \mid(i, j) \in E^{J i} ; i \in N^{\text {Japan }}, j \in \bar{N}^{\text {Japan }}\right\} \\
& \cup\left\{j \mid(j, i) \in E ; j \in N^{\text {Japan }}, i \in \bar{N}^{\text {Japan }}\right\} .
\end{aligned}
$$

5.5. Primary Maritime Flows between Japan and the World. From the primary flows (Figure $8, \Delta^{20}\left(N^{\text {Japan }}, \bar{N}^{\text {Japan }}\right)$ ) between Japan $\left(N^{\text {Japan }}\right)$ and the world $\left(\bar{N}^{\text {Japan }}\right)$, all prominent flows are to or from China $\left(N^{\text {China }}\right)$, Chinese Hong Kong, and Singapore. From the top 20 connections between Japan and the world (Table $\left.6, \Delta^{20}\left(N^{\text {Japan }}, \bar{N}^{\text {Japan }}\right)\right)$, the most prominent flows are active between Japan and the MSR (mainly Hong Kong, Singapore, and Malaysia in $N^{M S R}$ ). Hongkong and Singapore are essential hubs for Japanese products' trade; China is an essential market of Japanese industries.

The network flows between Japan $\left(N^{\text {Japan }}\right)$ and the world $\left(\bar{N}^{\text {Japan }}\right)$ can be computed (see Table 7$)$. By assessing the ratios of the flows between Japanese and the world as presented in the last two rows in Table 8, the flows of Japanese ports contribute less to the global maritime network (0.56 2.31\%), while contributing to its domestic trade dominantly (11.04 28.89\%).

5.6. Ranking Ports by Trading, Connection, and Centralities. Using the global connection data of the Japanese ports, we rank the ports, as shown in Table 7. Kobe is the first grade.

The Japanese ports are not different in terms of ranking of their throughput (using $C^{\text {degree }}(i)$ in Section 3) and network impact (using $C^{\text {pagerank }}(i)$ in Section 3) (see Table 9).

5.7. Primary Maritime Flows with the Maritime Silk Road. As seen from the primary maritime flows between Japan $\left(N^{\text {Japan }}\right)$ and the MSR $\left(N^{M S R}\right)$ (Figure 9), China, Singapore, and Malaysia are the central import countries connected to Japan.

From the top 20 connections between Japan and MSR $\left(\Delta^{20}\left(N^{\text {Japan }}, N^{M S R}\right)\right.$, Table 10$)$, we can identify three essential stakeholders: Hong Kong, Singapore, and Malaysia along the MSR.

Table 11 indicates the ratios of flows between Japan $\left(N^{\text {Japan }}\right)$ and the MSR $\left(N^{M S R}\right)$; about $20 \%$ of vessel flows of Japanese international trade are directed to the MSR, while Japan contributes to the MSR by a tiny ratio (from $0.52 \%$ to $4.49 \%$ ) of flows. It implies that although the BRI document 


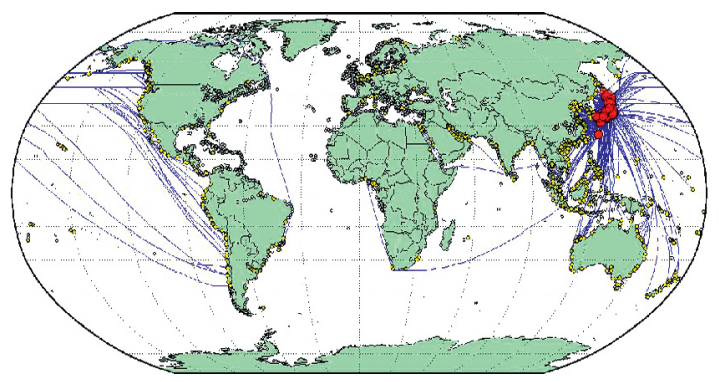

(a)

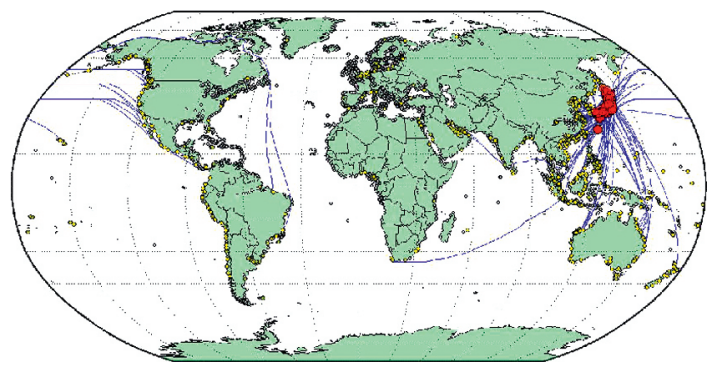

(c)

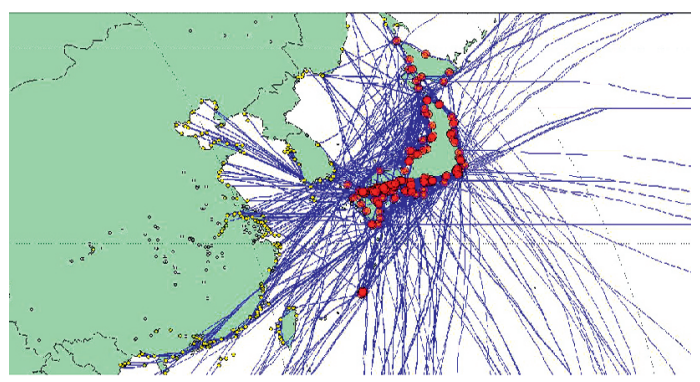

(b)

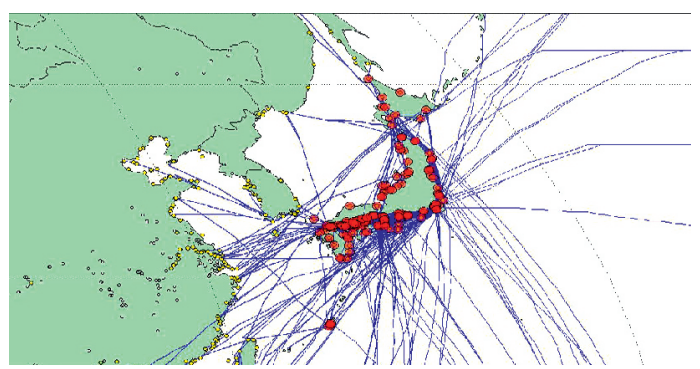

(d)

FIGURE 5: One-jump connections from Japanese ports to the world. (a) Global view (all). (b) Regional view (all). (c) Global view (top 2000). (d) Regional view (top 2000).

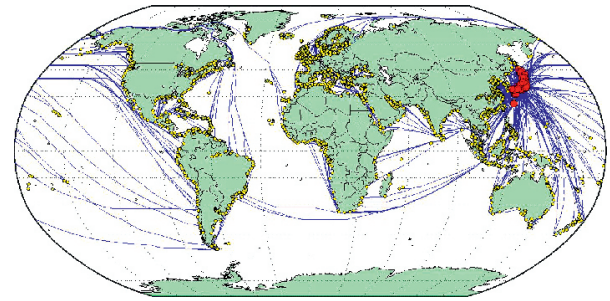

(a)

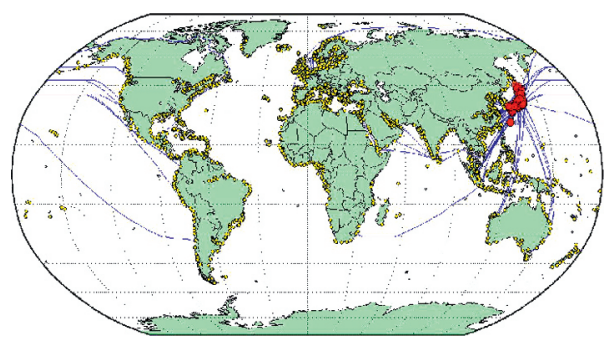

(c)

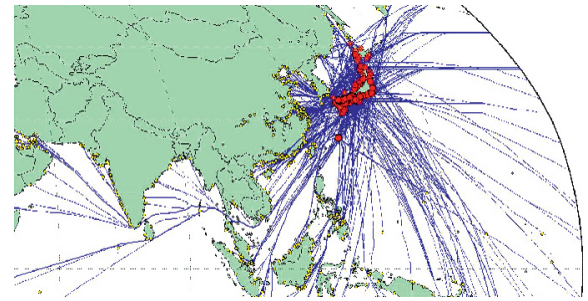

(b)

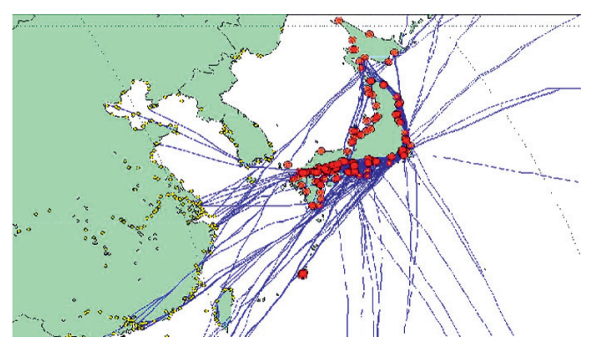

(d)

FiguRE 6: Multijump connections from Japanese ports. (a) Global view (all). (b) Regional view (all). (c) Global view (Top 2000). (d) Regional view (Top 2000).

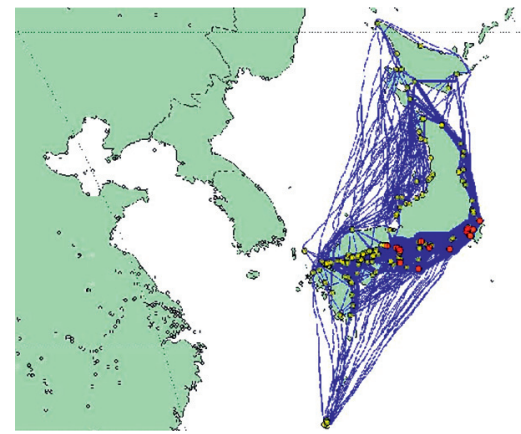

FIgURE 7: The network of the domestic connections among Japanese ports. 
TABLE 3: Domestic trading connections among Japanese ports.

\begin{tabular}{|c|c|c|c|c|c|}
\hline No & Port $i$ & $\left|N^{J d}\right|$ & $\left|E^{J d}\right|$ & Vessels $(i)$ & $C^{w d}(i)$ \\
\hline 1 & Kobe & 148 & 30803 & 641079 & 3889659765 \\
\hline 2 & Chiba & 148 & 31709 & 741774 & 3366894217 \\
\hline 3 & Higashi-Harima & 148 & 31411 & 661387 & 3326670783 \\
\hline 4 & Yokohama & 148 & 28089 & 526251 & 3238421359 \\
\hline 5 & Kawasaki & 148 & 29732 & 615061 & 3102537203 \\
\hline 6 & Tokyo & 148 & 24638 & 378676 & 2719177017 \\
\hline 7 & Osaka & 148 & 27932 & 499966 & 2680658048 \\
\hline 8 & Yura & 148 & 26314 & 397915 & 2612079462 \\
\hline 9 & Nagoya & 148 & 26425 & 392824 & 2480934235 \\
\hline 10 & Shingu & 148 & 26196 & 463112 & 20611 \\
\hline 11 & Atsumi & 148 & 25148 & 373972 & 2047806866 \\
\hline 12 & Omaezaki & 148 & 26578 & 425549 & 2009067062 \\
\hline 13 & Kurihama & 148 & 26087 & 360035 & 1704348133 \\
\hline 14 & Kashima & 148 & 25772 & 362319 & 1641696605 \\
\hline 15 & Wakayama & 148 & 25682 & 348348 & 1624227948 \\
\hline 16 & Kinuura & 148 & 23559 & 292885 & 1601320693 \\
\hline 17 & Sakai & 148 & 25455 & 369813 & 1580207446 \\
\hline 18 & Shimotsu & 148 & 25646 & 314510 & 1553780512 \\
\hline 19 & Kisarazu & 148 & 22072 & 252279 & 1452599256 \\
\hline \multirow[t]{6}{*}{20} & Yokkaichi & 148 & 24174 & 250812 & 1323937715 \\
\hline & Mean & 145 & 14416 & 117407 & 588070354 \\
\hline & Std & 7 & 7372 & 148324 & 785733186 \\
\hline & Median & 147 & 14140 & 56969 & 263031014 \\
\hline & Min & 95 & 1087 & 1488 & 9762340 \\
\hline & Max & 148 & 31709 & 741774 & 3889659765 \\
\hline
\end{tabular}

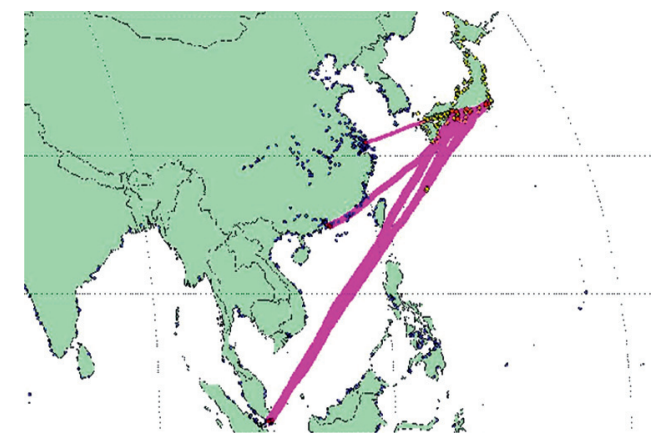

Figure 8: Primary flows between the Japanese ports and the world.

has not mentioned Japan, Japan has high connectivity with the BRI at least by the MSR.

5.8. Primary Maritime Flows with China. In the connections between Japan $\left(N^{\text {Japan }}\right)$ and China $\left(N^{\text {China }}\right)$ (see Figure 10 and Table 12), Hong Kong, Shanghai, Ningbo, and Guangzhou play essential roles. Although the flows between Japan and China account for $4.59 \sim 9.21 \%$ of Japan, while just $0.61 \sim 3.44 \%$ of China (see Table 13).

\section{Discussion}

Maritime networks are complex because they are agents of various stakeholders (port operators, ship operators, carriers, local port authorities and hinterlands, and multilevel governments). A port's structure and behaviors are results of games among these stakeholders, while the maritime
TABLE 4: Primary connections among the Japanese ports.

\begin{tabular}{lccccc}
\hline No & Port $1(i)$ & Port $2(j)$ & $F^{\text {seq }}(i, j)$ & $F^{\text {visit }}(i, j)$ & $F^{\text {weight }}(i, j)$ \\
\hline 1 & Kobe & Higashi- & 250 & 34949 & 220124245 \\
2 & Yokohama & Kawasaki & 285 & 42931 & 203249921 \\
3 & Kobe & Osaka & 262 & 31040 & 201807171 \\
4 & Kobe & Yura & 350 & 17253 & 188052477 \\
5 & Chiba & Kawasaki & 301 & 37817 & 183681995 \\
6 & Tokyo & Yokohama & 236 & 19043 & 178290254 \\
7 & Kobe & Tokyo & 230 & 13540 & 176306397 \\
8 & Kobe & Yokohama & 268 & 18386 & 169435330 \\
9 & Chiba & Yokohama & 260 & 31115 & 147186482 \\
10 & Kobe & Kawasaki & 255 & 18863 & 139285118 \\
11 & Nagoya & Tokyo & 232 & 11033 & 137489434 \\
12 & Chiba & Kobe & 307 & 21150 & 125182377 \\
13 & Nagoya & Yokohama & 268 & 13718 & 124939805 \\
14 & Higashi-H & Yura & 351 & 16247 & 124642033 \\
15 & Kobe & Nagoya & 265 & 12969 & 121850569 \\
16 & Tokyo & Yura & 232 & 10251 & 120032488 \\
17 & Osaka & Higashi-H & 237 & 24613 & 118952735 \\
18 & Osaka & Yura & 240 & 13184 & 116414044 \\
19 & Yokohama & Yura & 283 & 12341 & 115379092 \\
20 & Chiba & Higashi- & 247 & 21324 & 114699162 \\
& & Harima & & & \\
& & & & &
\end{tabular}

TABLE 5: International trading connections of Japanese ports.

\begin{tabular}{|c|c|c|c|c|c|}
\hline No & Port (i) & $N^{J i}$ & $F^{s e q}\left(i, N^{J i}\right)$ & $F^{v i s i t}\left(i, N^{J i}\right)$ & $F^{\text {weight }}\left(i, N^{J i}\right)$ \\
\hline 1 & Yokohama & 1700 & 32775 & 135776 & 3918894154 \\
\hline 2 & Kobe & 1877 & 36019 & 148559 & 3858658354 \\
\hline 3 & Yura & 1709 & 28592 & 97336 & 2936131922 \\
\hline 4 & Kawasaki & 1654 & 30115 & 119850 & 2664481393 \\
\hline 5 & Tokyo & 1272 & 20868 & 81832 & 2484460931 \\
\hline 6 & Chiba & 1525 & 22223 & 79823 & 2381060732 \\
\hline 7 & Nagoya & 1362 & 24272 & 82599 & 2044676910 \\
\hline 8 & $\begin{array}{l}\text { Higashi- } \\
\text { Harima }\end{array}$ & 1548 & 23966 & 84684 & 1908593486 \\
\hline 9 & Osaka & 1227 & 19578 & 72866 & 1743441359 \\
\hline 10 & Atsumi & 1342 & 22509 & 64844 & 1627764831 \\
\hline 11 & Yokkaichi & 1284 & 15458 & 36013 & 1265426014 \\
\hline 12 & Kurihama & 1402 & 20064 & 55552 & 1251518174 \\
\hline 13 & Kashima & 1413 & 14892 & 38522 & 1244728048 \\
\hline 14 & Shimotsu & 1374 & 17638 & 46588 & 1137514011 \\
\hline 15 & Hakodate & 1363 & 11926 & 25809 & 1123361951 \\
\hline 16 & Kinuura & 1270 & 17715 & 44918 & 1117380582 \\
\hline 17 & Shirashima & 1517 & 21622 & 69880 & 1099396186 \\
\hline 18 & Kisarazu & 1263 & 12905 & 27995 & 936574231 \\
\hline 19 & Omaezaki & 1088 & 16299 & 43395 & 765324362 \\
\hline 20 & Yokohama & 1700 & 32775 & 135776 & 3918894154 \\
\hline \multirow[t]{6}{*}{149} & Yanai & 1 & 3 & 3 & 13692 \\
\hline & Mean & 625 & 5856 & 14577 & 336818333 \\
\hline & Std & 427 & 7214 & 26068 & 688285152 \\
\hline & Median & 542 & 2994 & 3755 & 70536055 \\
\hline & Min & 1 & 3 & 3 & 13692 \\
\hline & Max & 1877 & 36019 & 148559 & 3918894154 \\
\hline
\end{tabular}

network in a country or region is a holistic emergency upon them. The real-world global maritime network consists of more than 6000 ports belonging to more than 200 economic entities. In the background of the maritime network, a lot of companies, organizations, and governments are involved. 
TABLE 6: Top 20 connections between Japan and the world.

\begin{tabular}{|c|c|c|c|c|c|c|}
\hline No & Japanese port $i$ & Maritime network & Top 20 port $j$ & $F^{s e q}(i, j)$ & $F^{v i s i t}(i, j)$ & $F^{\text {weight }}(i, j)$ \\
\hline 1 & Kobe & Singapore & Singapore & 134 & 5767 & 199498420 \\
\hline 2 & Yokohama & Singapore & Singapore & 129 & 5289 & 182321787 \\
\hline 3 & Yura & Singapore & Singapore & 133 & 4378 & 165408050 \\
\hline 4 & Yokohama & Hong Kong & Hong Kong & 167 & 5263 & 154132255 \\
\hline 5 & Tokyo & Hong Kong & Hong Kong & 164 & 5038 & 148066398 \\
\hline 6 & Chiba & Singapore & Singapore & 84 & 3091 & 144850261 \\
\hline 7 & Kawasaki & Singapore & Singapore & 91 & 5072 & 143696392 \\
\hline 8 & Kobe & Hong Kong & Hong Kong & 157 & 5107 & 140651890 \\
\hline 9 & Tokyo & Singapore & Singapore & 133 & 2825 & 115904354 \\
\hline 10 & Kobe & Malaysia & Pengerang Terminal & 121 & 2795 & 112761468 \\
\hline 11 & Nagoya & Singapore & Singapore & 123 & 3642 & 109875485 \\
\hline 12 & Chiba & Malaysia & Pengerang Terminal & 78 & 1642 & 103776273 \\
\hline 13 & Yura & Malaysia & Pengerang Terminal & 108 & 2164 & 100662393 \\
\hline 14 & Higashi-Harima & Singapore & Singapore & 83 & 2498 & 95781992 \\
\hline 15 & Yokohama & China & Chiwan & 152 & 2850 & 93425199 \\
\hline 16 & Kawasaki & Malaysia & Pengerang Terminal & 78 & 2526 & 92901159 \\
\hline 17 & Yura & Hong Kong & Hong Kong & 138 & 3173 & 91028161 \\
\hline 18 & Atsumi & Singapore & Singapore & 128 & 2685 & 90333871 \\
\hline 19 & Yokohama & Malaysia & Pengerang Terminal & 118 & 2459 & 87395691 \\
\hline 20 & Yokohama & China & Shanghai & 162 & 4702 & 84396110 \\
\hline
\end{tabular}

TABLE 7: Ranking Japanese ports by trading-related values.

\begin{tabular}{|c|c|c|c|c|c|}
\hline \multirow{2}{*}{ No } & \multirow{2}{*}{ Japanese port $i$} & \multicolumn{4}{|c|}{ Ranked by } \\
\hline & & $\left|N^{i o}(i)\right|$ & $F^{\text {seq }}\left(i, N^{\text {world }}\right)$ & $F^{\text {visit }}\left(i, N^{\text {world }}\right)$ & $F^{\text {weight }}\left(i, N^{\text {world }}\right)$ \\
\hline 1 & Kobe & Kobe & Kobe & Chiba & Kobe \\
\hline 2 & Yura & Yura & Yokohama & Kobe & Yokohama \\
\hline 3 & Yokohama & Yokohama & Kawasaki & Higashi-Harima & Kawasaki \\
\hline 4 & Kawasaki & Kawasaki & Higashi-Harima & Kawasaki & Chiba \\
\hline 5 & Shirashima & Higashi-Harima & Yura & Yokohama & Yura \\
\hline 6 & Higashi-Harima & Chiba & Chiba & Osaka & Higashi-Harima \\
\hline 7 & Nagoya & Shirashima & Nagoya & Shingu & Tokyo \\
\hline 8 & Chiba & Kashima & Atsumi & Yura & Nagoya \\
\hline 9 & Kisarazu & Kurihama & Osaka & Nagoya & Osaka \\
\hline 10 & Kurihama & Wakayama & Kurihama & Omaezaki & Atsumi \\
\hline 11 & Wakayama & Shimotsu & Tokyo & Tokyo & Kurihama \\
\hline 12 & Kinuura & Hakodate & Shimotsu & Atsumi & Kashima \\
\hline 13 & Atsumi & Nagoya & Omaezaki & Kurihama & Omaezaki \\
\hline 14 & Saganoseki & Atsumi & Kinuura & Kashima & Kinuura \\
\hline 15 & Tokyo & Yokkaichi & Kashima & Sakai & Shimotsu \\
\hline 16 & Amagasaki-NA & Tokyo & Wakayama & Wakayama & Yokkaichi \\
\hline 17 & Kashima & Kinuura & Shingu & Shimotsu & Shingu \\
\hline 18 & Omaezaki & Kisarazu & Yokkaichi & Komatsushima & Kisarazu \\
\hline 19 & Shimotsu & Saganoseki & Shirashima & Kinuura & Wakayama \\
\hline 20 & Yokkaichi & Osaka & Sakai & Takamatsu & Shirashima \\
\hline
\end{tabular}

TABLE 8: Ratios of flows between Japan and the world.

\begin{tabular}{lcccc}
\hline & Maritime network & $F^{\text {seq }}$ & $F^{\text {visit }}$ & $F^{\text {weight }}$ \\
\hline \multirow{3}{*}{ Flow } & $F^{J}=F^{*}\left(N^{\text {Japan }}, N^{\text {world }}\right)$ & 3020537 & 19665614 & $1.37808 E+11$ \\
& $F^{X}=F^{*}\left(N^{\text {Japan }}, \bar{N}^{\text {Japan }}\right)$ & 872595 & 2172000 & 50185931561 \\
& $F^{W}=F^{*}\left(N^{\text {world }}, N^{\text {world }}\right)$ & 37786321 & 390829144 & $3.89796 E+12$ \\
\hline \multirow{2}{*}{ Ratio (\%) } & $F^{X} / F^{J}$ & 28.89 & 11.04 & 36.42 \\
& $F^{X} / F^{W}$ & 2.31 & 0.56 & 1.29 \\
\hline
\end{tabular}

Their demands and benefits make the network alive and complicated in its structure and behaviors. The maritime networks are typically adaptive and complex, which indicates that no entity controls the network, or such control is finally impossible. The maritime network is a representative of related stakeholders. For example, a maritime 
TABle 9: Ranking the Japanese ports by degree and PageRank centralities.

\begin{tabular}{lccc}
\hline & Throughput $C^{\text {degree }}(i)$ & & Network impact $C^{\text {pagerank }}(i)$ \\
Rank & Port $i$ & Rank & Chiba \\
\hline 1 & Chiba & 1 & Higashi-Harima \\
2 & Higashi-Harima & 2 & Kobe \\
3 & Kobe & 3 & Kawasaki \\
4 & Kawasaki & 4 & Yokohama \\
5 & Yokohama & 5 & Osaka \\
6 & Osaka & 6 & Shingu \\
7 & Shingu & 7 & Omaezaki \\
8 & Omaezaki & 8 & Yura \\
9 & Yura & 9 & Nagoya \\
10 & Nagoya & 10 & Tokyo \\
11 & Tokyo & 11 & Sakai \\
12 & Atsumi & 12 & Atsumi \\
13 & Sakai & 13 & Kashima \\
14 & Kashima & 14 & Kurihama \\
15 & Kurihama & 15 & Wakayama \\
16 & Wakayama & 16 & Komatsushima \\
17 & Komatsushima & Shimotsu \\
18 & Shimotsu & 17 & Kinuura \\
19 & Kinuura & 18 & Takamatsu \\
20 & Takamatsu & 19 & 20 \\
\hline
\end{tabular}

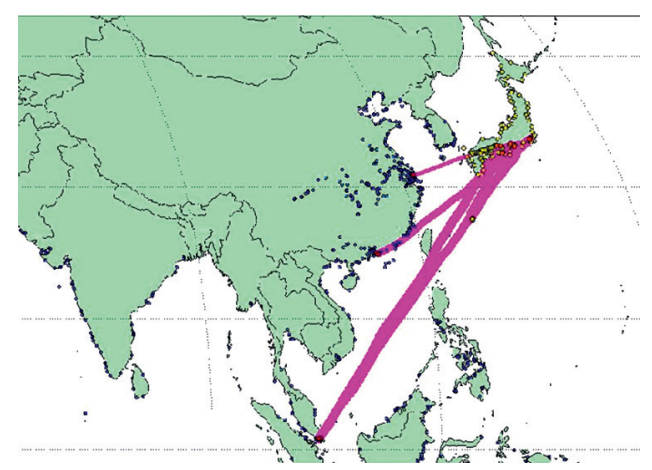

FIGURE 9: Primary flows between the Japanese ports and the MSR.

TABLE 10: Top 20 connections between Japan and the MSR.

\begin{tabular}{|c|c|c|c|c|c|c|}
\hline No & Japan port $(i)$ & Region & MSR port $(j)$ & $F^{s e q}(i, j)$ & $F^{\text {visit }}(i, j)$ & $F^{\text {weight }}(i, j)$ \\
\hline 1 & Kobe & Singapore & Singapore & 134 & 5767 & 199498420 \\
\hline 2 & Yokohama & Singapore & Singapore & 129 & 5289 & 182321787 \\
\hline 3 & Yura & Singapore & Singapore & 133 & 4378 & 165408050 \\
\hline 4 & Yokohama & Hong Kong & Hong Kong & 167 & 5263 & 154132255 \\
\hline 5 & Tokyo & Hong Kong & Hong Kong & 164 & 5038 & 148066398 \\
\hline 6 & Chiba & Singapore & Singapore & 84 & 3091 & 144850261 \\
\hline 7 & Kawasaki & Singapore & Singapore & 91 & 5072 & 143696392 \\
\hline 8 & Kobe & Hong Kong & Hong Kong & 157 & 5107 & 140651890 \\
\hline 9 & Tokyo & Singapore & Singapore & 133 & 2825 & 115904354 \\
\hline 10 & Kobe & Malaysia & Pengerang Terminal & 121 & 2795 & 112761468 \\
\hline 11 & Nagoya & Singapore & Singapore & 123 & 3642 & 109875485 \\
\hline 12 & Chiba & Malaysia & Pengerang Terminal & 78 & 1642 & 103776273 \\
\hline 13 & Yura & Malaysia & Pengerang Terminal & 108 & 2164 & 100662393 \\
\hline 14 & Higashi-Harima & Singapore & Singapore & 83 & 2498 & 95781992 \\
\hline 15 & Yokohama & China & Chiwan & 152 & 2850 & 93425199 \\
\hline 16 & Kawasaki & Malaysia & Pengerang Terminal & 78 & 2526 & 92901159 \\
\hline 17 & Yura & Hong Kong & Hong Kong & 138 & 3173 & 91028161 \\
\hline 18 & Atsumi & Singapore & Singapore & 128 & 2685 & 90333871 \\
\hline 19 & Yokohama & Malaysia & Pengerang Terminal & 118 & 2459 & 87395691 \\
\hline 20 & Shanghai & Japan & Yokohama & 162 & 4702 & 84396110 \\
\hline
\end{tabular}


TABLE 11: Ratios of flows between Japan and the Maritime Silk Road.

\begin{tabular}{lcccc}
\hline & Maritime network & $F^{\text {seq }}$ & $F^{\text {visit }}$ & $F^{\text {weight }}$ \\
\hline \multirow{3}{*}{ Flow } & $F^{J}=F^{*}\left(N^{\text {Japan }}, N^{\text {world }}\right)$ & 3020537 & 19665614 & $1.37808 E+11$ \\
& $F^{X}=F^{*}\left(N^{\text {Japan }}, N^{M S R}\right)$ & 566579 & 1565250 & 31290144747 \\
& $F^{M S R}=F^{*}\left(N^{M S R}, N^{\text {world }}\right)$ & 12627333 & 301703689 & $2.64665 E+12$ \\
\hline \multirow{2}{*}{ Ratio (\%) } & $F^{X} / F^{J}$ & 18.76 & 7.96 & 22.71 \\
& $F^{X} / F^{M S R}$ & 4.49 & 0.52 & 1.18 \\
\hline
\end{tabular}

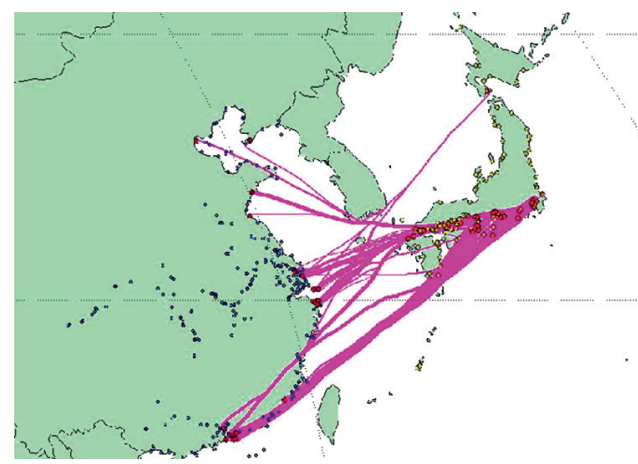

Figure 10: Primary flows between Japan and China.

TABle 12: Top 20 connections between Japan and China.

\begin{tabular}{|c|c|c|c|c|c|}
\hline No & Chinese port $(i)$ & Japanese port $(j)$ & $F^{s e q}(i, j)$ & $F^{\text {visit }}(i, j)$ & $F^{\text {weight }}(i, j)$ \\
\hline 1 & Hong Kong & Yokohama & 167 & 5263 & 154132255 \\
\hline 2 & Hong Kong & Tokyo & 164 & 5038 & 148066398 \\
\hline 3 & Hong Kong & Kobe & 157 & 5107 & 140651890 \\
\hline 4 & Chiwan & Yokohama & 152 & 2850 & 93425199 \\
\hline 5 & Hong Kong & Yura & 138 & 3173 & 91028161 \\
\hline 6 & Shanghai & Yokohama & 162 & 4702 & 84396110 \\
\hline 7 & Hong Kong & Nagoya & 135 & 3242 & 83980715 \\
\hline 8 & Yangshan & Yokohama & 62 & 1000 & 75735976 \\
\hline 9 & Hong Kong & Osaka & 147 & 3459 & 72617308 \\
\hline 10 & Shanghai & Kobe & 182 & 5458 & 71786723 \\
\hline 11 & Shanghai & Tokyo & 168 & 3809 & 71102550 \\
\hline 12 & Chiwan & Tokyo & 155 & 2694 & 66382585 \\
\hline 13 & Ningbo & Yokohama & 95 & 1616 & 65644572 \\
\hline 14 & Chiwan & Kobe & 140 & 2608 & 64020112 \\
\hline 15 & Qingdao & Yokohama & 128 & 2124 & 63518997 \\
\hline 16 & Guangzhou & Yokohama & 175 & 1843 & 55636718 \\
\hline 17 & Hong Kong & Atsumi & 149 & 2280 & 55437416 \\
\hline 18 & Shanghai & Osaka & 187 & 3804 & 53315366 \\
\hline 19 & Yantian & Yokohama & 93 & 837 & 50783540 \\
\hline \multirow[t]{2}{*}{20} & Shanghai & Kawasaki & 152 & 3447 & 50111425 \\
\hline & 269 Chinese ports & 149 Japanese ports & & & \\
\hline
\end{tabular}

TABle 13: Ratios of flows between China and Japan.

\begin{tabular}{lcccc}
\hline & Maritime network & $F^{\text {seq }}$ & $F^{\text {visit }}$ & $F^{\text {weight }}$ \\
\hline \multirow{2}{*}{ Flow } & $F^{J}=F^{*}\left(N^{\text {Japan }}, N^{\text {world }}\right)$ & 3020537 & 19665614 & $1.37808 E+11$ \\
& $F^{X}=F^{*}\left(N^{\text {Japan }}, N^{\text {China }}\right)$ & 278311 & 902653 & 12468012503 \\
& $F^{\text {China }}=F^{*}\left(N^{\text {China }}, N^{\text {world }}\right)$ & 8083920 & 284973537 & $2.05516 E+12$ \\
\hline \multirow{2}{*}{ Ratio (\%) } & $F^{X} / F^{J}$ & 9.21 & 4.59 & 9.05 \\
& $F^{X} / F^{\text {China }}$ & 3.44 & 0.32 & 0.61 \\
\hline
\end{tabular}


network of the ports of a country delegates the benefits and powers of the country. Therefore, we use the maritime network to analyze the relations and behaviors of the stakeholders.

Some studies formulated the maritime ports a maritime network by methods in network sciences (see Table 1). The ports interconnect with each other by shipping liners or vessel movements. Mainly, centrality-based methods are used to reveal the port significances in the network and impacts on the network. Network-based statistics help reveal network-level structures and behaviors [1]. The pioneering studies seldom investigate the countries or regional port systems in the global maritime network by data-driven methods due to that constructing large-scale or global maritime networks is challenging. This article results in the linkage between the maritime network and the country-level stakeholders in the context of the global maritime network.

Geographically, Japan is isolated from the land covered by the BRI and MSR while it has many connections with China, Asia, and Eurasia by seaborne trades. In the results presented in Section 5, although Japanese ports account for less vessel flows in the global maritime system, the interaction flow between Japan and China (also the MSR) is prominent when comparing the overall flows of Japan while it is just a small portion of the flows of China and MSR. The study provides enough reasons for Japan considering the essential connections with the MSR and Eurasia. In Section 3 , the network definitions and analysis tools are formulated corresponding to a series of quantitative computing methods by extending the concepts and algorithms in network sciences. We take Japan, China, MSR, and the world maritime system as typical maritime networks here, and so we can analyze the interactions among the maritime networks of various countries or independent economies embedded in a global network in similar ways.

\section{Conclusion}

In this article, we addressed the research question: how do the maritime networks represent the country- and regionlevel interactions in the context of the global maritime network? We examined the interactions between Japan marine ports and the MSR by a data system and analysis tools. Japan connects with the MSR closely by seaborne transportation; a network of maritime networks contributes to the implications of interacted economical entities represented by the maritime networks, especially in the context of the global maritime network; prominent interactions among the maritime networks emerge by using the nodeand edge-based network analysis tools. We construct a sample of a global maritime network with more than 6000 maritime ports to test and confirm the study. Although there are pioneering studies using methods in network sciences to investigate maritime networks (see Table 1), this article is the first large-scale study to link country-level and regional level analysis and maritime networks upon a global maritime network.
This study makes several scholarly contributions. It examines maritime network interactions embedded in a global maritime network, where the maritime networks are agents for country-level and regional level entities, e.g., Japan, China, MSR, and the world maritime system. Besides, it is a first ever study to examine the interactions through maritime ports and shipping between Japan and China (and MSR and the world) using a reliable method in association with AIS data. In particular, although most studies of maritime networks use data of container liner shipping as a base, this article uses a novel secondary dataset that captures the port and vessel profile data and the vessels' global movement tracks (AIS). This comprehensive dataset reflects the diversification in empirical methods in the big data and artificial intelligence era [40]. While the ports and shipping data and the AIS data have been used extensively in transport and resource management areas, we developed definitions and tools for the data-driven maritime networks.

There are limitations in the data and methods applied to this study. We construct the networks using the data of 2016, while the maritime system evolves in the economic and trade systems in recent years. To obtain a concise large-scale maritime network, we must process, repair, and synthesize by many steps. The data and its processing are expensive and time-consuming at the present stage of this study. The data system will finally provide benchmark datasets for maritime networks that will be assessable by academic communities. Therefore, the data chain is so long to guarantee and test the data quality. We focused on the application methods based on network sciences to constructed networks. However, the present developed analysis methods cannot handle the uncertainty, dynamics, and even random errors of the realworld maritime networks completely [41]. The stakeholders at the national and regional levels are complicated, and their observations and decisions must be affected by various sources of information. The maritime networks should integrate with various sources in holistic decision-making environments.

Several future studies would be desirable. First, we can extend the proposed models to examine other economy-, policy-, and sustainability-related impacts of maritime network interactions on regional and global maritime networks. At the port, national, and regional levels, the impacts are different and mutually affected. It is beneficial to construct a multilayer network for studying the evolutionary behaviors of the networks of subnetworks [35, 42]. Second, we mainly extend the network presentation, generation, and necessary analyzing concepts and methods, which can be further verified and promoted in generalized networks, especially by coupling with methods in complex systems. Third, we use the maritime networks that are generated by a set of ports in the global maritime network. In the view of network structure, we may use community detection and clustering algorithms to develop self-adaptive and evolutionary maritime networks by using the developed data system. It may contribute to new algorithms in network analysis. In summary, this study is the start of studying the network of networks. 


\section{Data Availability}

The data used to support the findings of this study are available from the corresponding author upon reasonable request.

\section{Conflicts of Interest}

The authors declare that they have no conflicts of interest.

\section{Acknowledgments}

The National Natural Science Foundation of China (71871136) and the Science and Technology Commission of Shanghai Municipality (17DZ2280200) partially supported this study.

\section{References}

[1] Z.-H. Hu, "Vietnam's connectivity and embeddedness in the maritime silk road and global maritime network," IEEE Access, vol. 7, no. 1, pp. 79592-79601, 2019.

[2] A. Sardain, E. Sardain, and B. Leung, "Global forecasts of shipping traffic and biological invasions to 2050," Nature Sustainability, vol. 2, no. 4, pp. 274-282, 2019.

[3] P. T.-W. Lee, Z.-H. Hu, S.-J. Lee, K.-S. Choi, and S.-H. Shin, "Research trends and agenda on the Belt and Road (B\&R) initiative with a focus on maritime transport," Maritime Policy \& Management, vol. 45, no. 3, pp. 282-300, 2018.

[4] P. T.-W. Lee, S.-W. Lee, Z.-H. Hu, K.-S. Choi, N. Y. H. Choi, and S.-H. Shin, "Promoting Korean international trade in the east Sea economic rim in the context of the Belt and road initiative," Journal of Korea Trade, vol. 22, no. 3, pp. 212-227, 2018.

[5] National Development and Reform Commission (NRDC) of China, Vision and Actions on Jointly Building Silk Road Economic Belt and 21st-Century, 2015, http://en.ndrc.gov.cn/ newsrelease/201503/t20150330_669367.html.

[6] Y. Wangping and L. Xiaolu, "Study on the interaction between China and Japan's economy based on FDI, import and export trade," Studies in Business and Economics, vol. 13, no. 1, pp. 194-208, 2018.

[7] S. Nanwani, "Belt and road initiative: responses from Japan and India - bilateralism, multilateralism and collaborations," Global Policy, vol. 10, no. 2, pp. 284-289, 2019.

[8] A. Ito, "China's belt and road initiative and Japan's response: from non-participation to conditional engagement," East Asia, vol. 36, no. 2, pp. 115-128, 2019.

[9] Z. H. Hu, C. J. Liu, W. Chen, Y. G. Wang, and C. Wei, "Maritime convection and fluctuation between Vietnam and China: a data-driven study," Research in Transportation Business and Management, 2019.

[10] D. A. Kroodsma, J. Mayorga, T. Hochberg et al., "Tracking the global footprint of fisheries," Science, vol. 359, no. 6378, pp. 904-908, 2018.

[11] D. Karamshuk, F. Shaw, J. Brownlie, and N. Sastry, "Bridging big data and qualitative methods in the social sciences: a case study of Twitter responses to high profile deaths by suicide," Online Social Networks and Media, vol. 1, no. 1, pp. 33-43, 2017.

[12] V. Boldosova, "Deliberate storytelling in big data analytics adoption," Information Systems Journal, vol. 29, no. 6, pp. 1126-1152, 2019.
[13] A. Ojo and B. Heravi, "Patterns in award winning data storytelling," Digital Journalism, vol. 6, no. 6, pp. 693-718, 2018.

[14] R. Albert and A.-L. Barabási, "Statistical mechanics of complex networks," Reviews of Modern Physics, vol. 74, no. 1, pp. 47-97, 2002.

[15] L. C. Freeman, "Centrality in social networks conceptual clarification," Social Networks, vol. 1, no. 3, pp. 215-239, 1978.

[16] Z. Bu, Y. Wang, H.-J. Li, J. Jiang, Z. Wu, and J. Cao, "Link prediction in temporal networks: integrating survival analysis and game theory," Information Sciences, vol. 498, no. 1, pp. 41-61, 2019.

[17] J. Cao, Z. Bu, Y. Wang, H. Yang, J. Jiang, and H.-J. Li, "Detecting prosumer-community groups in smart grids from the multiagent perspective," IEEE Transactions on Systems, Man, and Cybernetics: Systems, vol. 49, no. 8, pp. 1652-1664, 2019.

[18] M. E. J. Newman and M. Girvan, "Finding and evaluating community structure in networks," Physical Review E-Statistical, Nonlinear, and Soft Matter Physics, vol. 69, no. 2, 2004.

[19] A. Arenas, A. Díaz-Guilera, J. Kurths, Y. Moreno, and C. Zhou, "Synchronization in complex networks," Physics Reports, vol. 469, no. 3, pp. 93-153, 2008.

[20] Z. Wang, Q. Guo, S. Sun, and C. Xia, "The impact of awareness diffusion on SIR-like epidemics in multiplex networks," Applied Mathematics and Computation, vol. 349, no. 1, pp. 134-147, 2019.

[21] R. Agarwal and O. Ergun, "Ship scheduling and network design for cargo routing in liner shipping," Transportation Science, vol. 42, no. 2, pp. 175-196, 2008.

[22] Q. Meng, S. Wang, H. Andersson, and K. Thun, "Containership routing and scheduling in liner shipping: overview and future research directions," Transportation Science, vol. 48, no. 2, pp. 265-280, 2014.

[23] D. Tsiotas and S. Polyzos, "Analyzing the maritime transportation system in Greece: a complex network approach," Networks and Spatial Economics, vol. 15, no. 4, pp. 981-1010, 2015.

[24] Y. Wang and K. Cullinane, "Determinants of port centrality in maritime container transportation," Transportation Research Part E: Logistics and Transportation Review, vol. 95, no. 1, pp. 326-340, 2016.

[25] M. Xu, Z. Li, Y. Shi, X. Zhang, and S. Jiang, "Evolution of regional inequality in the global shipping network," Journal of Transport Geography, vol. 44, no. 1, pp. 1-12, 2015.

[26] C. P. Montesn, M. J. F. Seoane, and F. G. Laxe, "General cargo and containership emergent routes: a complex networks description," Transport Policy, vol. 24, no. 1, pp. 126-140, 2012.

[27] N. K. Tran and H.-D. Haasis, "Empirical analysis of the container liner shipping network on the East-West corridor (1995-2011)," NETNOMICS: Economic Research and Electronic Networking, vol. 15, no. 3, pp. 121-153, 2014.

[28] N. M. Viljoen and J. W. Joubert, "The vulnerability of the global container shipping network to targeted link disruption," Physica A: Statistical Mechanics and Its Applications, vol. 462, no. 1, pp. 396-409, 2016.

[29] A. Calatayud, J. Mangan, and R. Palacin, "Vulnerability of international freight flows to shipping network disruptions: a multiplex network perspective," Transportation Research Part E: Logistics and Transportation Review, vol. 108, no. 1, pp. 195-208, 2017.

[30] C. Liu, J. Wang, and H. Zhang, "Spatial heterogeneity of ports in the global maritime network detected by weighted ego 
network analysis," Maritime Policy \& Management, vol. 45, no. 1, pp. 89-104, 2018.

[31] N. Mou, C. Liu, L. Zhang et al., "Spatial pattern and regional relevance analysis of the maritime silk road shipping network," Sustainability, vol. 10, no. 4, p. 977, 2018.

[32] P. Peng, S. Cheng, J. Chen et al., "A fine-grained perspective on the robustness of global cargo ship transportation networks," Journal of Geographical Sciences, vol. 28, no. 7, pp. 881-889, 2018.

[33] D. Tsiotas and S. Polyzos, "Effects in the network topology due to node aggregation: empirical evidence from the domestic maritime transportation in Greece," Physica A: Statistical Mechanics and Its Applications, vol. 491, no. 1, pp. 71-88, 2018.

[34] S. Inoue, "Realities and challenges of port alliance in Japanports of Kobe and Osaka," Research in Transportation Business \& Management, vol. 26, no. 1, pp. 45-55, 2018.

[35] J. Xu, T. L. Wickramarathne, and N. V. Chawla, "Representing higher-order dependencies in networks," Science Advances, vol. 2, no. 5, Article ID e1600028, 2016.

[36] Y. Luo, L. Wang, S. Sun, and C. Xia, "Community detection based on local information and dynamic expansion," IEEE Access, vol. 7, no. 8515203, pp. 8142773-8142786, 2018.

[37] J. Wang, C. Li, and C. Xia, "Improved centrality indicators to characterize the nodal spreading capability in complex networks," Applied Mathematics and Computation, vol. 334, no. 1, pp. 388-400, 2018.

[38] S. Brin and L. Page, "The anatomy of a large-scale hypertextual web search engine," Computer Networks and ISDN Systems, vol. 30, no. 1-7, pp. 107-117, 1998.

[39] M. Scholz, J. Pfeiffer, and F. Rothlauf, "Using PageRank for non-personalized default rankings in dynamic markets," European Journal of Operational Research, vol. 260, no. 1, pp. 388-401, 2017.

[40] V. Singhal, B. B. Flynn, P. T. Ward, A. V. Roth, and V. Gaur, "Editorial: empirical elephants-Why multiple methods are essential to quality research in operations and supply chain management," Journal of Operations Management, vol. 26, no. 3, pp. 345-348, 2008.

[41] H.-J. Li, H. Wang, and L. Chen, "Measuring robustness of community structure in complex networks," EPL (Europhysics Letters), vol. 108, no. 6, p. 68009, 2014.

[42] C. Xia, Z. Wang, C. Zheng et al., "A new coupled diseaseawareness spreading model with mass media on multiplex networks," Information Sciences, vol. 471, no. 1, pp. 185-200, 2019. 